\title{
25-hydroxycholecalciferol reverses heat induced alterations in bone quality in finisher broilers associated with effects on intestinal integrity and inflammation
}

Huaiyong Zhang ${ }^{1,2 \dagger}$, Maryam Majdeddin ${ }^{1 \dagger}$, Djoere Gaublomme ${ }^{3}$, Bernard Taminiau ${ }^{4}$, Matthieu Boone ${ }^{5,6}$, Dirk Elewaut ${ }^{3}$, George Daube $^{4}$, Iván Josipovic ${ }^{5}$, Keying Zhang ${ }^{2}$ and Joris Michiels ${ }^{1 *}$ (i)

\begin{abstract}
Background: Alterations in ambient temperature have been associated with multiple detrimental effects on broilers such as intestinal barrier disruption and dysbiosis resulting in systemic inflammation. Inflammation and 25hydroxycholecalciferol $\left(25-\mathrm{OH}-\mathrm{D}_{3}\right)$ have shown to play a negative and positive role, respectively, in the regulation of bone mass. Hence the potential of $25-\mathrm{OH}-\mathrm{D}_{3}$ in alleviating heat induced bone alterations and its mechanisms was studied.

Results: Heat stress (HS) directly induced a decrease in tibia material properties and bone mass, as demonstrated by lower mineral content, and HS caused a notable increase in intestinal permeability. Treatment with dietary $25-\mathrm{OH}-\mathrm{D}_{3}$ reversed the HS-induced bone loss and barrier leak. Broilers suffering from HS exhibited dysbiosis and increased expression of inflammatory cytokines in the ileum and bone marrow, as well as increased osteoclast number and activity. The changes were prevented by dietary $25-\mathrm{OH}-\mathrm{D}_{3}$ administration. Specifically, dietary $25-\mathrm{OH}-\mathrm{D}_{3}$ addition decreased abundance of B- and T-cells in blood, and the expression of inflammatory cytokines, especially TNF-a, in both the ileum and bone marrow, but did not alter the diversity and population or composition of major bacterial phyla. With regard to bone remodeling, dietary $25-\mathrm{OH}-\mathrm{D}_{3}$ supplementation was linked to a decrease in serum C-terminal cross-linked telopeptide of type I collagen reflecting bone resorption and a concomitant decrement in osteoclast-specific marker genes expression (e.g. cathepsin K), whereas it did not apparently change serum bone formation markers during HS.
\end{abstract} Conclusions: These data underscore the damage of HS to intestinal integrity and bone health, as well as that dietary $25-\mathrm{OH}-\mathrm{D}_{3}$ supplementation was identified as a potential therapy for preventing these adverse effects.

Keywords: Bone remodeling, HS, Inflammation, Intestinal barrier, Tibial mass

\footnotetext{
* Correspondence: joris.michiels@ugent.be

${ }^{\dagger}$ Huaiyong Zhang and Maryam Majdeddin contributed equally to this work. ${ }^{1}$ Laboratory for Animal Nutrition and Animal Product Quality, Department of Animal Sciences and Aquatic Ecology, Ghent University, 9000 Ghent, Belgium Full list of author information is available at the end of the article
}

(c) The Author(s). 2021 Open Access This article is licensed under a Creative Commons Attribution 4.0 International License, which permits use, sharing, adaptation, distribution and reproduction in any medium or format, as long as you give appropriate credit to the original author(s) and the source, provide a link to the Creative Commons licence, and indicate if changes were made. The images or other third party material in this article are included in the article's Creative Commons licence, unless indicated otherwise in a credit line to the material. If material is not included in the article's Creative Commons licence and your intended use is not permitted by statutory regulation or exceeds the permitted use, you will need to obtain permission directly from the copyright holder. To view a copy of this licence, visit http://creativecommons.org/licenses/by/4.0/. The Creative Commons Public Domain Dedication waiver (http://creativecommons.org/publicdomain/zero/1.0/) applies to the data made available in this article, unless otherwise stated in a credit line to the data. 


\section{Introduction}

Heat stress (HS) is well documented to have a negative influence on livestock productivity and climate change may exacerbate the incidence of HS. Fast-growing modern broilers with intensive metabolic heat production, covering feathers and lack of sweat glands are particularly prone to HS due to limited capability for heat dissipation [1]. One of the most noticeable developmental problems associated with HS in all poultry is a pronounced induction of leg abnormalities, as shown in broilers [2, 3], laying hens [4], and turkeys [5]. Consequently, the incidence of leg disorders, such as lameness, causes economic losses to the producer [6], and this is also a welfare issue, resulting from pain and modified behavior [7].

The aetiology of gait problems in poultry induced by HS is varied and complex. An obvious cause of that reduction in bone quality and mass is associated with deficient calcium ( $\mathrm{Ca}$ ) consumption as HS reduces feed intake (FI) and nutrient absorption [8]. Further, elevated temperatures impair gut integrity, thereby increasing systemic inflammation that elicits osteoclastic bone resorption [9]. It has been reported that HS directly affects gut integrity and induces the activation of the innate immune system resulting in systemic inflammation in bovine [10], rats [11], and laying hens [12]. Moreover, heat tends to alter the gut microbiome of caged laying hens [12] and broilers [13, 14]. In mice, using standard tools for manipulation of the gut microbiota, i.e. germfree and oral antibiotics or probiotics, to alter the microbiota composition are related to changes in bone development and remodeling, as well as changes in bone mechanical strength through actions on the immune system, endocrine system and $\mathrm{Ca}$ absorption [9, 15]. For instance, by comparing germ-free mice with conventionally raised mice it was shown that the presence of microbiota led to lower trabecular and cortical bone mass [16]. A further alteration in gut microbiota via oral antibiotics has been reported to affect bone density in mice [17]. Meanwhile, germ-free mice were showing a reduced number of osteoclasts and lower level of Interleukin (IL)-6, receptor activator of nuclear factor-k $B$ ligand (RANKL), tumor necrosis factor alpha (TNF$\alpha)$, and $C D 4^{+} \mathrm{T}$ cells in bone $[18,19]$. These features were normalized by colonization with gut microbiota from conventionally raised mice [19]. This suggests that the interaction between gut microbiota and the immune system may play a significant role in bone metabolism [9]. In addition, excess glucocorticoids [20] and/or reactive oxygen substances [21] evoked by elevated temperatures interfered with bone formation and resorption, contributing to skeletal damage. However, direct evidences of HS modifying bone health, especially bone remodeling, in broilers are largely lacking.
Several nutritional strategies such as supplementation of diets with tomato pomace and symbiotic product have been used to attenuate the negative effects of HS on bone health in broilers [2, 3]. Vitamin D, a lipid-soluble vitamin, is proposed to improve the walking ability and bone quality, and consequently decrease leg diseases in broilers $[22,23]$. Its deficiency can lead to a higher incidence of leg problems in birds [24]. In addition to stimulation of $\mathrm{Ca}$ and phosphate $(\mathrm{P})$ absorption in the intestine and renal reabsorption [25], and direct regulation of bone formation and resorption $[26,27]$, the beneficial effects that vitamin $\mathrm{D}$ in bone metabolism may exert may also be related to its many other biological effects, including interference with gut microbiota, and antioxidant and anti-inflammatory properties $[28,29]$. All these factors may contribute to bone metabolism $[9,15,30]$. For instance, the administration of vitamin $\mathrm{D}$ was noticed to abolish the effects of lipopolysaccharides (LPS) by restoring the expression of zonula occludens (ZO)-1 and claudin-2 [31], and had a protective effect against pepsin-trypsin-resistant gliadin induced tight junction injuries both in vitro and in vivo [32]. Vitamin $D_{3}$ is also associated with the changes in the composition of gut microbiota, most likely by regulating immune and inflammatory responses [28]. Binding of the active form of vitamin $\mathrm{D}_{3}$ was found to induce production of antimicrobial peptides by macrophages, resulting in a selective killing of pathogenic bacteria and increasing the opportunity for colonization with "beneficial" bacteria [33]. A recent review outlines that vitamin $\mathrm{D}_{3}$ could promote an increase in the activities of the antioxidant enzymes including superoxide dismutase (SOD), glutathione peroxidase (GSH-Px) and catalase in clinical trials [29], and a decrease in reactive oxygen species (ROS) propagation of monocytes [34]. Based on above findings, we, therefore, hypothesized that dietary vitamin $\mathrm{D}_{3}$ supplementation could reverse HS-induced bone loss in finishing broilers by a complex interaction of different mechanisms.

In the present study, we firstly confirmed the HS model in broiler during the finisher phase. HS was induced by a cycling heat episode at $34^{\circ} \mathrm{C}$ for $7 \mathrm{~h}$ daily for $17 \mathrm{~d}$, opposed to the thermoneutral condition at $22^{\circ} \mathrm{C}$ as in the control group. We elucidated the responses in bone quality and intestinal barrier to this long-term HS. Subsequently, 25-hydroxycholecalciferol (25-OH-D $)$, a vitamin $\mathrm{D}_{3}$ metabolite, was chosen based on the fact that $25-\mathrm{OH}-\mathrm{D}_{3}$ is approximately twice as active as cholecalciferol (vitamin $\mathrm{D}_{3}$ ) in promoting bone strength [35] and thus we evaluated the effects of $25-\mathrm{OH}-\mathrm{D}_{3}$ on similar endpoints in broilers subjected to HS.

\section{Materials and methods}

\section{Birds and study design}

Animal procedures were approved by the Ethics Committee of the Faculty of Veterinary Medicine, Ghent 
University (Belgium) for the humane care and use of animals in research (approval No. 2019-87). Male chicks from the Ross 308 strain (Vervaeke-Belavi, Tielt, Belgium) were housed in floor pens $(1.0 \times 0.9 \mathrm{~m})$ in a climate-controlled facility. The temperature in the room was $34^{\circ} \mathrm{C}$ for the first week and then gradually lowered to $22^{\circ} \mathrm{C}$ by $22 \mathrm{~d}$ based on normal management practices. The light schedule was $23 \mathrm{~L}: 1 \mathrm{D}$ and $18 \mathrm{~L}: 6 \mathrm{D}$ (18 L from 04:00 to 22:00) during 1-7 $\mathrm{d}$ and beyond, respectively. The broilers were vaccinated at $1 \mathrm{~d}$ of age against Newcastle Disease and Infectious Bronchitis at the hatchery facilities. At $18 \mathrm{~d}$ of age the vaccination against Newcastle Disease was repeated with Nobilis ND Clone 30 by spraying. At $15 \mathrm{~d}$ of age, birds with mean $0.48 \pm 0.003 \mathrm{~kg}$ body weight $(\mathrm{BW})$, were randomly into 4 treatment groups: (1) the control group (Ctrl; constant $22^{\circ} \mathrm{C}$ from $22 \mathrm{~d}$ onward and ad libitum feeding the basal diets, $n=$ 7 ), (2) the HS with ad libitum intake (from $22 \mathrm{~d}$ onward $34{ }^{\circ} \mathrm{C}$ for $7 \mathrm{~h}$ daily with $\mathrm{RH}$ between $50 \%$ and $60 \%$ and the rest of day at $26^{\circ} \mathrm{C}, n=9$ ), (3) the pair-fed group (PF; constant $22^{\circ} \mathrm{C}$ from $22 \mathrm{~d}$ onward and pair-fed to HS group), and (4) the $25-\mathrm{OH}-\mathrm{D}_{3}$ diet ad libitum under $\mathrm{HS}\left(\mathrm{HS}+25-\mathrm{OH}-\mathrm{D}_{3} ; n=10\right)$; the $25-\mathrm{OH}-\mathrm{D}_{3}$ concentration was $0.069 \mathrm{mg} / \mathrm{kg}$ diet and provided by DSM Ltd. (DSM Nutritional Products, Basel, Switzerland). Each replicate consisted of 12 birds (density of $13.3 \mathrm{birds} / \mathrm{m}^{2}$ ) and number of replicates per treatment was established based on statistical power analysis. Dietary regimes were followed in grower and finisher phase (15-21 d) and finisher phase (22-39 d). Pair feeding of PF was established in finisher period by measuring daily FI of HS group, and providing this amount the next day in three meals across the light hours of the day. PF was included to decipher whether the effects of HS are solely due to reduced FI or not. The chronic cyclic HS was thus implemented in the finisher phase (22-39 d) as shown in Fig. 1A. Diets included starter (1-14 d), grower (15-21 d) and finisher (22-39 d) diets, and were supplied as pellets (Table S1). The dry matter (DM), crude protein $(\mathrm{CP})$, ether extract, ash, $\mathrm{Ca}$, and $\mathrm{P}$ of diets were analyzed as described elsewhere [36]. Vitamin $\mathrm{D}_{3}$ and $25-\mathrm{OH}-\mathrm{D}_{3}$ in diets were quantitated by DSM Nutritional Products (Basel, Switzerland). Specifically, after saponification with potassium hydroxide alkaline ethanol solution and extraction with cyclohexane solvent, vitamin $D_{3}$ was quantified by a reversed-phase high pressure liquid chromatography with tandem mass spectrometry (HPLCMSMS) using 6, 19, 19-trideuterocitamin $D_{3}$ as stable isotope labelled internal standard. For $25-\mathrm{OH}-\mathrm{D}_{3}$, after addition of the internal standard, the sample was saponified and $25-\mathrm{OH}-\mathrm{D}_{3}$ was extracted with methyl tert-butyl ether. Then, the extract was dried by evaporation and then analyzed with reversed phase HPLC-MSMS detection. The quantification was carried out by using $\mathrm{d} 6-25-$ hydroxy cholecalciferol as internal standard. The results of dietary nutrient analysis confirmed proper preparation of experimental diets (Table S2).

\section{Sample collection and procedures}

In the present study, BW, FI, and mortality by pen were recorded at 15, 22, and $39 \mathrm{~d}$. BW gain and feed conversion as the feed to gain ratio (F: G) was calculated on a per-pen basis. Panting frequency and rectal temperature of three birds randomly taken from each pen were measured at $\mathrm{d}$ 23, 30 and 38 as described by Majdeddin et al. [37]. Two birds per pen with weight close to average weight of the pen were sampled on d 39 ( $4 \mathrm{~h}$ after starting high temperature for birds from the HS room). The 1st bird was used for sample collection after euthanasia using sodium pentobarbital $(30 \mathrm{mg} / \mathrm{kg}$ of $\mathrm{BW})$ injected intravenously via the brachial vein. Blood was taken by puncture in the heart with $80 \mathrm{~mm}$ needle $22 \mathrm{G}$ and divided it into three parts, one part was immediately dropped into $K_{2}$ EDTA-tube used for fixation of blood by the addition of Transfix ${ }^{\circ}$ reagent (Caltag Medsystems, Ltd., UK) for whole blood, another part was thrown into $\mathrm{K}_{2}$ EDTA-anticoagulant tubes and then centrifuged at 3,000 $\times g / 15 \mathrm{~min}$ at $4{ }^{\circ} \mathrm{C}$ to obtain plasma, and the last one was centrifuged at $4,000 \times g / 15 \mathrm{~min}$ at $4{ }^{\circ} \mathrm{C}$ for serum after complete coagulation, and subsequently mid-duodenal and mid-ileal (removing one centimeter right in the middle for histology analysis) mucosa, kidney, caecal contents, left tibia (the proximal end), and tibial marrow were collected, then snap frozen in liquid nitrogen and stored $\left(-80^{\circ} \mathrm{C}\right)$ until analysis. Thymus, spleen, and bursa of Fabricius were excised and weighed, and calculated as relative weight of organ $(\mathrm{g} / 100 \mathrm{~g} \mathrm{BW})$. Right tibia and mid-ileum were dissected and rapidly immersed in phosphate-buffered formaldehyde for histology analysis. The 2nd bird was also euthanized, and the left tibia was removed for micro computed tomography (Micro-CT) analysis. The right tibia was harvested, length, and width (at 50\% of length) of tibia were measured after removal of soft tissues.

\section{Gait score}

After d 39, birds remained subjected to their respective HS or thermoneutral condition, and on d 40 , walking ability of 3 randomly selected birds per pen was scored on a 6-point scale from 0 (completely normal) to 5 (unable to stand) according to the method of Knowles et al. [38]. Each bird was encouraged to walk approximately $10 \mathrm{~m}$. The use of a stick was gently employed if the bird showed hesitation or unwillingness. The evaluator sat on the floor at eye level viewing the back of the broiler's legs and then scored.

\section{Gut permeability}

Gut permeability was evaluated by determining the ability of fluorescein isothiocyanate dextran (FITC-d; $4 \mathrm{kDa}$, 


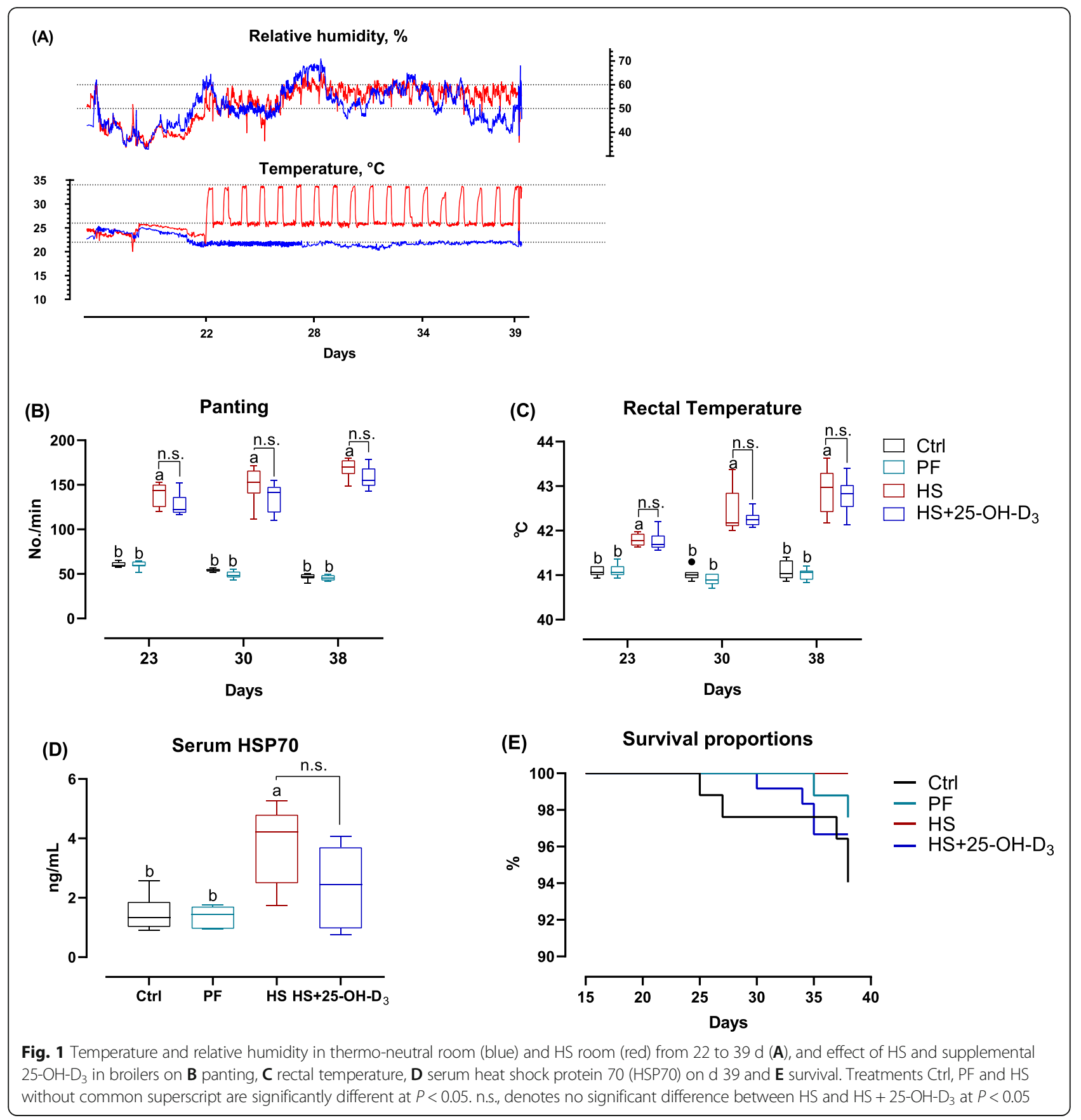

Sigma, Overijse, Belgium) to cross from the intestinal lumen into circulation [39]. On d 40, 33 birds (1 chicken per pen) close to the pen average weight were selected, and all chickens received orally FITC-d $(4.16 \mathrm{mg} / \mathrm{kg})$. Blood was collected at $1 \mathrm{~h}$ post FITC-d administration and the fluorescence of serum FITC-d was determined using a Thermo Fluoroskan Ascent FL fluorometer (Thermo Scientific, Merelbeke, Belgium) at excitation and emission wavelengths of 485 and $530 \mathrm{~nm}$, respectively.
The content of FITC-d was calculated from standard curves generated by the serial dilution of FITC-d.

\section{Blood hematology and biochemistry}

Freshly drawn fixated whole bloods from $39 \mathrm{~d}$ were used to assess numbers of thrombocytes and white blood cell differentials as outlined by Seliger et al. [40]. This automated analysis of chicken blood is based on flow cytometry using an anti-CD45 monoclonal antibody in 
combination with selected subset specific markers. Serum heat shock protein (HSP70) was analyzed using ELISA kit (Chicken Heat Shock Protein 70, CSBE11196Ch, Cusabio, Wuhan, China). Plasma 25-OH-D 3 and $24(\mathrm{R}), 25-(\mathrm{OH})_{2}-\mathrm{D}_{3}$ concentrations were determined by using reversed phase HPLC-MSMS detection (DSM Nutritional Products, Basel, Switzerland). Plasma P was determined by ammonium molybdate (Abbott Laboratories, Germany). Plasma Ca was determined by the chromogenic complex formed between $\mathrm{Ca}$ ions and o-cresol phthalein (MAK022; Sigma-Aldrich, Overijse, Belgium). As bone turnover markers, C-terminal cross-linked telopeptide of type I collagen (CTx) in plasma was measured using an immunoassay (Cobas; Roche Diagnostics) with a LOQ of $10 \mathrm{ng} / \mathrm{L}$. Plasma alkaline phosphatase (ALP) was measured by catalyzing the hydrolysis of colorless $p$-nitrophenyl phosphate to give $p$-nitrophenol using commercially available assay kits (Abbott Laboratories, Germany).

\section{Mechanical testing of tibia}

After the measurements of length and width, all right tibias were used for bone quality analysis. Biomechanical testing was performed by the 3-point bending method using a Mecmesin BFG $25000 \mathrm{~N}$ force gauge (Mecmesin, Slinfold, UK) at a constant $50 \mathrm{~kg}$ load cell. Each bone was loaded on its anterior aspect, at the mid-point between the bottom supports, at the precise mid-point along its length. Loading proceeded at a constant rate $(12 \mathrm{~mm} / \mathrm{min})$ up to the breaking of the bone. Forcedisplacement data were collected to calculate whole bone stiffness (slope of the linear portion of the loaddisplacement curve), yield load, fracture load and areaunder-the-curve (AUC). The yield point was defined as the load at which the load-deformation relationship ceased to be linear [41].

\section{Fat-free weight, density and ash content of tibia}

After mechanical testing, the tibia of each bird was used for tibial fat-free weight $(\mathrm{g})$ and density $\left(\mathrm{g} / \mathrm{cm}^{3}\right)$, which was defined as bone fat free weight $(\mathrm{g})$ divided by tibial volume $\left(\mathrm{cm}^{3}\right)$. In detail, after removing the bone marrow cavities liquid with absorbent paper, the tibia volume was measured based on the quantum of water overflowing from a fully filled container when the measured tibia was inserted into a $100 \mathrm{~mL}$ cylinder, Hereafter, these bone samples were air-dried for $24 \mathrm{~h}$ at room temperature, extracted by ethyl ether for $48 \mathrm{~h}$, ovendried at $108^{\circ} \mathrm{C}$ for $24 \mathrm{~h}$ for dry defatted bone weight determination. Subsequently, dry-defatted tibia was ashed in a muffle furnace at $550^{\circ} \mathrm{C}$ for $24 \mathrm{~h}$ and the ash was measured on the basis of the percentage of dry-defatted weight.

\section{Micro-CT}

The left tibia was prepared for micro-CT imaging. To avoid an influence of the water content within the bone, soft tissue was removed from the tibia and then tibia was dried at $65^{\circ} \mathrm{C}$. Preliminary tests showed that the procedure did not affect the imaging process. Furthermore, it allowed for a more uniform positioning. The samples were imaged in the custom-designed micro-CT scanner HECTOR of the Ghent University Center for Xray Tomography (UGCT; www.ugct.ugent.be) [42]. For each micro-CT scan, 2,001 projection images were acquired at an exposure time of $1,000 \mathrm{~ms}$ for each projection, covering the full $360^{\circ}$ angular range. A tube voltage of $130 \mathrm{kV}$ was employed at $10 \mathrm{~W}$ target power. An additional filter of $0.5 \mathrm{~mm} \mathrm{Al}$ was used to reduce beam hardening effects. Using geometrical magnification, the reconstructed isotropic voxel size was $22^{3} \mu \mathrm{m}^{3}$. Projection data were reconstructed to a stack of $2 \mathrm{D}$ slices using the in-house developed reconstruction platform Octopus Reconstruction [43]. Next, the micro-CT images were analyzed using custom-written scripts in Image J (National Institutes of Health, USA). The volume of interested cortical bone was chosen from the tibial mid-diaphysis and extended proximal-distally for a total length of $37 \mathrm{~mm}$. The center of the diaphysis of the tibia was automatically classified into trabeculae, cortex and 'total cortex' (including pores), using an algorithm similar to that of Buie et al. [44]. The total volume and the volume of cortical bone and trabecular bone were quantified, and bone volume to total volume ratio (BV/ TV), cortical thickness and trabecular thickness were calculated. To measure the trabecular bone in the proximal end of the tibia (metaphysis), a region $4 \mathrm{~mm}$ in length was determined, starting $9 \mathrm{~mm}$ below the surface of the condyles. To exclude denser cortical regions at the bone surface, the outer $0.5 \mathrm{~mm}$ of the bone surface was removed from the region of interest. The BV/TV of trabecular bone and trabecular thickness were calculated. The average thickness of the structures was measured using the thickness plugin from Bone J [45].

\section{lleum and bone histological analysis}

Formalin-fixed ileal samples were dehydrated, embedded, sliced into 5- $\mu \mathrm{m}$ transects, and stained with hematoxylin and eosin (H\&E), and subsequently villus height (V) and crypt depth (C) of at least ten welloriented villi, were measured and the ratio of villus height to crypt depth (V/C) was calculated [46]. In addition, to identify osteoclast count on the external surface of the bone, the fixed proximal tibia samples were decalcified in 14\% EDTA ( $\mathrm{pH}$ 7.4) for $21 \mathrm{~d}$, embedded in paraffin, frontally sectioned into $10-\mu \mathrm{m}$ slices, and subjected to tartrate-resistant acid phosphatase (TRAP) bone staining using the leukocyte acid phosphatase assay 
kit (Sigma-Aldrich, Overijse, Belgium) according to the instructions. All histomorphometry data acquisition was performed using an Olympus BX61 microscope and image analysis software (Olympus, Aartselaar, Belgium).

\section{Oxidative stress}

The buffered aqueous extracts of ileal mucosae were prepared after mixing with $1 \%$ Triton X-100 phosphate buffer ( $\mathrm{pH} 7 ; 50 \mathrm{mmol} / \mathrm{L}$ ), and then homogenized, centrifuged, and filtrated. Subsequently, total malonaldehyde (MDA) content in buffered aqueous extracts and plasma were tested using the thiobarbituric acid reactive substances test according to the method of Grotto et al. [47] with slight modifications using spectrophotometry at $532 \mathrm{~nm}$. The GSH-Px activity of buffered aqueous extracts and plasma, defined as the amount of sample $(\mathrm{g})$ required to oxidize $1 \mu \mathrm{mol}$ of 2, 4-dinitrophenylhydrazine (DNPH) per minute at $25^{\circ} \mathrm{C}$, were quantified based on the dynamical alteration in the oxidation of NADPH and reaction time using Multi-Mode Microplate Readers at $340 \mathrm{~nm}$ [48]. The SOD activity represented as percentage inhibition of autoxidation of pyrogallol was determined by observing the increase in absorbance at $420 \mathrm{~nm}$ for $5 \mathrm{~min}$ by spectrophotometry [49].

\section{Gene expression assays}

Total RNA was extracted from the duodenal and ileal mucosa, kidney, tibia and marrow using the Trizol reagent (Sigma-Aldrich, Overijse, Belgium) and RNA concentrations were quantified using a spectrophotometer (Nanodrop 2000; Thermo Fisher Scientific Inc., Merelbeke, Belgium). First-strand complementary DNA (Cdna) was reverse-transcribed from $200 \mathrm{ng}$ of total RNA using the PrimeScript ${ }^{\text {Ti }}$ RT Reagent Kit (RR037A, Takara; Saint-Germain-en-Laye, France). The obtained cDNA was used to determine the mRNA expression of genes of interest by ABI 7500 RT-PCR detection system (Applied Biosystems, Merelbeke, Belgium), using Fast SYBR Green Master Mix (Takara, Saint-Germain-enLaye, France). Primers were designed using Primer 3 (Table S3). The standard curve method was used to estimate reaction efficiency (slope). Relative gene expression was quantified by normalizing to the expression of glyceraldehyde-3-phosphate dehydrogenase (GAPDH) and $\beta$-actin mRNA, with Ctrl equaling to around 1.

\section{Gut microbiome analysis}

The microbial composition of caecal contents was evaluated by $16 \mathrm{~S}$ ribosomal RNA (rRNA) profiling. Specifically, genomic DNA was extracted using PSP Spin Stool DNA Plus Kit (Invitek, Westburg, Netherlands) according to the manufacturer's instructions. After evaluation of DNA concentration and purity, the V1-V3 hypervariable region of the bacterial $16 \mathrm{~S}$ rRNA was amplified using the specific primer (Forward primer: 5 '-GAGAGT TTGATYMTGGCTCAG-3' and reverse primers: 5'ACCGCGGCTGCTGGCAC-30). Based upon the purified PCR products, Illumina sequencing libraries were generated using V3 chemistry kit and sequenced on an Illumina Miseq platform (Illumina, San Diego, USA). The obtained sequences were processed using MOTHUR (software package v1.39.5) for alignment and clustering [50], while the VSEARCH algorithm was utilized for chimera detection [51]. The final reads were clustered as operational taxonomic units (OTUs) with a 97\% similarity threshold. The OTUs were further assigned to species level using the BLASTN algorithm based on the SILVA database (v1.32) of full-length $16 \mathrm{~S}$ rRNA sequences [52]. The alpha diversity was evaluated with MOTHUR at the genus level by calculating the Chao1 richness index (richness), reciprocal Simpson biodiversity index (diversity), and Simpson evenness index (evenness). Beta-diversity at genus level was estimated by calculating Bray-Curtis dissimilarity and visualized with principal co-ordinates analysis (PCoA). Sequences generated in the current study have been deposited in the NCBI database under the accession number PRJNA694510.

\section{Cecal short-chain fatty acid (SCFA) analysis}

Cecal contents were weighted, and approximately $1 \mathrm{~g}$ was dissolved in $5.5 \mathrm{~mL} 10 \%$ formic acid containing 0.5 mg ethyl butyric acid as the internal standard. After filtration and centrifugion the supernatants were used to determine total SCFA, acetate, propionate, butyrate, isobutyrate, valerate, and iso-valerate concentrations using a gas chromatography on a Shimadzu 2010 (Shimadzu Corporation, 's-Hertogenbosch, The Netherlands) equipped with a flame ionization detector. The conditions were used as described previously [53].

\section{Statistical analyses}

The data obtained were analyzed by the Shapiro-Wilk and Levene's test to assess normal distribution and homogeneity of variances. One-way ANOVA followed by Tukey's test for multiple comparisons (normal distribution) or Kruskal-Wallis test followed by Dunn's multiple comparisons (non-normal distribution) was performed to elucidate a potential response by HS among Ctrl, PF, and HS groups on performance and physiological indices. Differences between HS and HS + 25- $\mathrm{OH}-\mathrm{D}_{3}$ groups were evaluated using a two-tailed unpaired $t$-test or the Mann-Whitney $\mathrm{U}$ test for normally or non-normally distributed datasets, respectively. For estimating mortality, survival curves were constructed using Kaplan-Meier method and statistically analyzed by the log-rank test for trend. Values are given as mean \pm standard error. Differences in alpha diversity metrices 
were evaluated similarly. Permutational multivariate analysis of variance was applied to test the effect of treatment on overall community composition on Bray-Curtis distance. $P<0.05$ was considered statistically significant. A trend was regarded as $P<0.1$.

\section{Results}

\section{Growth performance}

As illustrated in Fig. 1, implementing the chronic cyclic HS to broilers from 22 to $39 \mathrm{~d}$ (Fig. 1A) increased the respiratory rate expressed as panting and rectal temperature at 23, 30, and $38 \mathrm{~d}$ of age (Fig. 1B, C; $P<$ 0.05), as well as serum HSP70 concentration at $39 \mathrm{~d}$ (Fig. 1D; $P<0.01$ ) as compared with Ctrl or PF birds. Dietary 25-OH- $\mathrm{D}_{3}$ supplementation did not affect panting, rectal temperature, serum HSP70 and survival in comparison to HS (Fig. 1B-E; $P>0.05$ ).

Data of growth performance show that HS notably decreased BW at $39 \mathrm{~d}, \mathrm{BW}$ gain and FI (22 to $39 \mathrm{~d})(P<$ 0.05 ), but it did not affect F: G. HS effects on production were at the levels of PF. However, PF birds had higher F: $\mathrm{G}$ than Ctrl birds (from 22 to $39 \mathrm{~d}, P<0.05$ ). The birds supplemented with $25-\mathrm{OH}-\mathrm{D}_{3}$ had higher $\mathrm{BW}$ at $39 \mathrm{~d}$ and BW gain (22 to $39 \mathrm{~d}$ ) than the birds fed without 25 $\mathrm{OH}-\mathrm{D}_{3}$ during HS (Table 1; $P<0.05$ ). Regarding mortality, neither $\mathrm{HS}$ or $25-\mathrm{OH}-\mathrm{D}_{3}$ changed mortality $(P>$ 0.05 ), i.e. bead birds were $5 / 84$ (birds died/total birds), 2/84, 0/108, and 4/120 in Ctrl, PF, HS, and HS + 25-OH$\mathrm{D}_{3}$ group, respectively (Fig. 1E).

\section{Gait score and bone characteristics}

As shown in Table 2, HS did not result in difference in gait score, but dietary supplementation with $25-\mathrm{OH}-\mathrm{D}_{3}$ improved the walking ability of birds under HS $(P<$ $0.05)$. The positive outcome for $25-\mathrm{OH}-\mathrm{D}_{3}$ was not associated with tibial growth, evidenced by similar tibia length, width, and fat-free weight. Mechanical testing analysis indicated a decrease in the mechanical properties in HS birds, i.e. lower fracture load in HS compared with Ctrl and PF birds $(P<0.05)$, which was restored by supplementation of $25-\mathrm{OH}-\mathrm{D}_{3}(P<0.05)$. Also, HS did not affect tibia slope compared to Ctrl and PF groups, but slope was increased by supplementing $25-\mathrm{OH}-\mathrm{D}_{3}$ to heat-stressed birds $(P<0.01)$. Additionally, HS reduced both yield load and AUC to a level that was not significantly different from control birds, which was slightly prevented with dietary $25-\mathrm{OH}-\mathrm{D}_{3}$ treatment (both $P>0.05$ ).

Moreover, HS broilers exhibited decreased ash $(P<$ $0.01)$ and density $(P=0.055)$ of tibia compared with Ctrl and PF birds, and birds fed $25-\mathrm{OH}-\mathrm{D}_{3}$ diets yielded increased mineral deposition of tibia evidenced by increased ash and density when compared with HS broilers (both $P<0.05$ ). Further analysis with micro-CT showed that BV/TV and thickness of both trabecular and cortical bone in the diaphysis was not notably affected by HS as compared with Ctrl or PF broilers $(P>0.05)$. Under the HS condition, dietary $25-\mathrm{OH}-\mathrm{D}_{3}$ supplementation remarkably increased the

Table 1 Effect of HS and supplemental 25-hydroxycholecalciferol (25-OH-D $)$ on performances of broilers

\begin{tabular}{|c|c|c|c|c|}
\hline Items & Ctrl & $\mathrm{PF}$ & HS & $\mathrm{HS}+25-\mathrm{OH}-\mathrm{D}_{3}$ \\
\hline \multicolumn{5}{|l|}{ BW, $g$} \\
\hline $15 d$ & $483.7 \pm 0.53$ & $483.7 \pm 1.00$ & $483.9 \pm 0.80$ & $483.1 \pm 0.88$ \\
\hline $21 d$ & $1,028.6 \pm 22.96$ & $1,027.1 \pm 32.54$ & $1,027.8 \pm 13.82$ & $1,024.3 \pm 17.34$ \\
\hline $39 d$ & $3,080.9 \pm 45.66^{a}$ & $2,779.4 \pm 33.65^{b}$ & $2,827.4 \pm 55.83^{b}$ & $2,888.5 \pm 57.91^{*}$ \\
\hline \multicolumn{5}{|l|}{ Gain, $\mathrm{g}$} \\
\hline $15-21 d$ & $544.9 \pm 23.04$ & $543.4 \pm 32.61$ & $543.9 \pm 13.76$ & $541.3 \pm 15.33$ \\
\hline $22-39 d$ & $2,052.3 \pm 40.82^{a}$ & $1,752.3 \pm 29.80^{b}$ & $1,799.6 \pm 55.68^{b}$ & $1,864.1 \pm 67.93^{*}$ \\
\hline $15-39 d$ & $2,518.2 \pm 159.18^{a}$ & $2,276.1 \pm 66.46^{b}$ & $2,343.5 \pm 56.27^{b}$ & $2,373.7 \pm 79.41$ \\
\hline \multicolumn{5}{|l|}{$\mathrm{Fl}, \mathrm{g}$} \\
\hline $15-21 d$ & $704.7 \pm 14.94$ & $713.8 \pm 20.17$ & $706.8 \pm 9.39$ & $709.8 \pm 19.02$ \\
\hline $22-39 d$ & $3,133.7 \pm 39.93^{a}$ & $2,783.4 \pm 55.54^{b}$ & $2,785.5 \pm 39.25^{b}$ & $2,837.5 \pm 68.95$ \\
\hline $15-39 d$ & $3,711.3 \pm 214.42^{a}$ & $3,464.6 \pm 46.25^{b}$ & $3,490.6 \pm 48.52^{b}$ & $3,498.6 \pm 124.70$ \\
\hline \multicolumn{5}{|l|}{$F: G, g / g$} \\
\hline $15-21 d$ & $1.29 \pm 0.030$ & $1.32 \pm 0.046$ & $1.30 \pm 0.024$ & $1.31 \pm 0.043$ \\
\hline $22-39 d$ & $1.53 \pm 0.014^{b}$ & $1.59 \pm 0.028^{a}$ & $1.55 \pm 0.043^{\mathrm{ab}}$ & $1.52 \pm 0.033$ \\
\hline $15-39 d$ & $1.47 \pm 0.013^{b}$ & $1.52 \pm 0.029^{a}$ & $1.49 \pm 0.030^{b}$ & $1.47 \pm 0.027$ \\
\hline
\end{tabular}

Data represent means with standard error;

Treatments Ctrl, PF and HS without common superscript are significantly different at $P<0.05 .{ }^{*}$ denotes significant difference between $\mathrm{HS}$ and $\mathrm{HS}+25-\mathrm{OH}-\mathrm{D}_{3}$ at $P<0.05$;

$B W$ Body weight, FI Feed intake, F: G Feed intake to gain ratio 
Table 2 Effect of HS and supplemental 25-hydroxycholecalciferol $\left(25-\mathrm{OH}-\mathrm{D}_{3}\right)$ on gait score $(\mathrm{d} 40)$ and tibia bone characteristics (d 39) of broilers

\begin{tabular}{|c|c|c|c|c|}
\hline Items & Ctrl & PF & HS & $\mathrm{HS}+25-\mathrm{OH}-\mathrm{D}_{3}$ \\
\hline Gait score & $2.10 \pm 0.28$ & $1.38 \pm 0.11$ & $1.93 \pm 0.23$ & $1.37 \pm 0.12^{*}$ \\
\hline \multicolumn{5}{|l|}{ Bone growth } \\
\hline Length, mm & $104.96 \pm 1.80$ & $103.26 \pm 1.47$ & $105.30 \pm 1.11$ & $105.31 \pm 1.07$ \\
\hline Width, mm & $9.70 \pm 0.23$ & $9.96 \pm 0.20$ & $9.39 \pm 0.21$ & $9.50 \pm 0.25$ \\
\hline Fat-free weight, $\mathrm{g}$ & $7.53 \pm 0.25$ & $7.51 \pm 0.16$ & $7.29 \pm 0.18$ & $7.29 \pm 0.15$ \\
\hline \multicolumn{5}{|l|}{ Bone mineralization } \\
\hline Ash, \%Fat-free weight & $45.71 \pm 0.26^{\mathrm{a}}$ & $46.08 \pm 0.41^{a}$ & $43.91 \pm 0.59^{b}$ & $45.92 \pm 0.42^{*}$ \\
\hline Density, $\mathrm{g} / \mathrm{mL}$ & $0.45 \pm 0.01$ & $0.44 \pm 0.01$ & $0.42 \pm 0.01$ & $0.45 \pm 0.01^{*}$ \\
\hline Cortical thickness in diaphysis, $\mu \mathrm{m}$ & $25.18 \pm 1.80$ & $26.06 \pm 2.39$ & $24.32 \pm 0.96$ & $28.25 \pm 1.65^{*}$ \\
\hline BV/TV in diaphysis, \% & $0.56 \pm 0.01$ & $0.55 \pm 0.01$ & $0.54 \pm 0.01$ & $0.55 \pm 0.01$ \\
\hline Trabecular thickness in metaphysis, $\mu \mathrm{m}$ & $4.14 \pm 0.05$ & $4.17 \pm 0.09$ & $4.19 \pm 0.05$ & $4.32 \pm 0.03^{*}$ \\
\hline BV/TV in metaphysis, \% & $0.25 \pm 0.01$ & $0.27 \pm 0.03$ & $0.24 \pm 0.01$ & $0.25 \pm 0.01$ \\
\hline \multicolumn{5}{|l|}{ Bone mechanical properties } \\
\hline Fracture load, $\mathrm{N}$ & $708.33 \pm 23.86^{\mathrm{a}}$ & $725 \pm 28.14^{a}$ & $587.5 \pm 33.74^{b}$ & $707.14 \pm 33.5^{*}$ \\
\hline Yield load, N & $710.65 \pm 77.63$ & $678.56 \pm 42.13$ & $594.27 \pm 51.06$ & $769.00 \pm 69.67$ \\
\hline Slope, N/mm & $310.91 \pm 62.24$ & $324.98 \pm 82.38$ & $296.30 \pm 24.34$ & $472.13 \pm 50.13^{*}$ \\
\hline$A \cup C, N \times m m \times 10^{3}$ & $3.36 \pm 0.36$ & $3.14 \pm 0.39$ & $2.63 \pm 0.21$ & $3.15 \pm 0.34$ \\
\hline
\end{tabular}

Data represent means with standard error;

Treatments Ctrl, PF and HS without common superscript are significantly different at $P<0.05$. denotes significant difference between $\mathrm{HS}$ and $\mathrm{HS}+25-\mathrm{OH}-\mathrm{D}_{3}$ at $P<0.05$;

AUC Area under the load-displacement curve, BV/TV Bone volume/Total volume

cortical thickness in diaphysis and the trabecular thickness in metaphysis $(P<0.05)$, although it did not apparently change the BV/TV of both diaphysis and metaphysis.

\section{$\mathrm{Ca}$, $\mathrm{P}$, and vitamin $\mathrm{D}_{3}$ homeostasis}

Regarding the homeostasis of $\mathrm{Ca}, \mathrm{P}$, and vitamin $\mathrm{D}_{3}$, differences in plasma $25-\mathrm{OH}-\mathrm{D}_{3}$ concentration were found between Ctrl, PF, and HS groups $(P<0.01)$, but 24(R), 25- $(\mathrm{OH})_{2}-\mathrm{D}_{3}$ and the ratio of $24(\mathrm{R}), 25-(\mathrm{OH})_{2}-\mathrm{D}_{3}$ to 25-OH- $\mathrm{D}_{3}$ were similar among Ctrl, $\mathrm{PF}$ and $\mathrm{HS}$ groups (Fig. 2A-C). Dietary $25-\mathrm{OH}-\mathrm{D}_{3}$ addition markedly elevated plasma $\mathrm{Ca}, 25-\mathrm{OH}-\mathrm{D}_{3}$ and $24(\mathrm{R}), 25-(\mathrm{OH})_{2}-\mathrm{D}_{3}$ levels (Fig. 2A-D; $P<0.05$ ). In addition, compared with Ctrl broilers, birds from HS and PF groups displayed decreased Ca content $(P<0.05)$ and comparable levels of plasma $\mathrm{P}(P>0.05)$ (Fig. 2D). No difference was observed among Ctrl, $\mathrm{PF}$, and HS groups in terms of the mRNA expressions of vitamin $\mathrm{D}$ receptor $(V D R)$ and sodiumdependent phosphorus transport protein IIb $(\mathrm{NaPi}-\mathrm{IIb})$ in the duodenum and kidney, neither of calbindin-1 in the kidney (Fig. 2E; $P>0.05$ ). However, heat exposure resulted in downregulated calbindin-1 mRNA abundance in the duodenum when compared to Ctrl, but not when compared to PF groups $(P<0.05)$. Dietary $25-\mathrm{OH}-\mathrm{D}_{3}$ addition markedly increased mRNA expression of the duodenal VDR (trend, $P=0.052$ ) and calbindin-1 (Fig. 2E).

\section{Intestinal barrier}

Direct assessment of permeability using FITC-d suggests that HS significantly increased intestinal permeability, evidenced by higher serum FITC-d concentration (Fig. 3A; $P<0.05$ ). Further examination of $\mathrm{V}$ and $\mathrm{C}$ confirmed that HS birds had a distinct decreased $\mathrm{V}(P<$ $0.05)$, but unaffected $C$, and a tendency $(P=0.075)$ to decrease $\mathrm{V} / \mathrm{C}$ ratio relative to Ctrl broilers (Fig. 3B-E). Analysis of the tight junction proteins (TJPs) shows that the expression of ZO-1 and claudin-1 was decreased in HS compared with Ctrl or PF birds (Fig. 3F, G; $P<0.05$ ), and mRNA of mucin-2 was downregulated (Fig. $3 \mathrm{H} ; P<$ 0.05). 25-OH- $\mathrm{D}_{3}$ treatment prevented HS-induced increases in permeability, and decreases in $\mathrm{V}, \mathrm{V} / \mathrm{C}$ ratio, and TJPs and mucin-2 transcription (Fig. 3).

\section{Caecal microbiome}

Concerning the effects of HS and 25-OH- $\mathrm{D}_{3}$ on the caecal microbiome, the genus evenness (Simpson evenness index) and diversity (Simpson index) (both $P<0.05$ ), but not richness (Chaol index) (trend, $P=0.064$ ) in the HS group were decreased compared with those in Ctrl and/ or PF groups (Fig. 4A-C). According to the PCoA plot, the samples in the HS group did not form a distinct cluster from those in the PF group, but was separated from those in the Ctrl group (Fig. 4D). The compositions of caecal microbiota at phylum level differed 

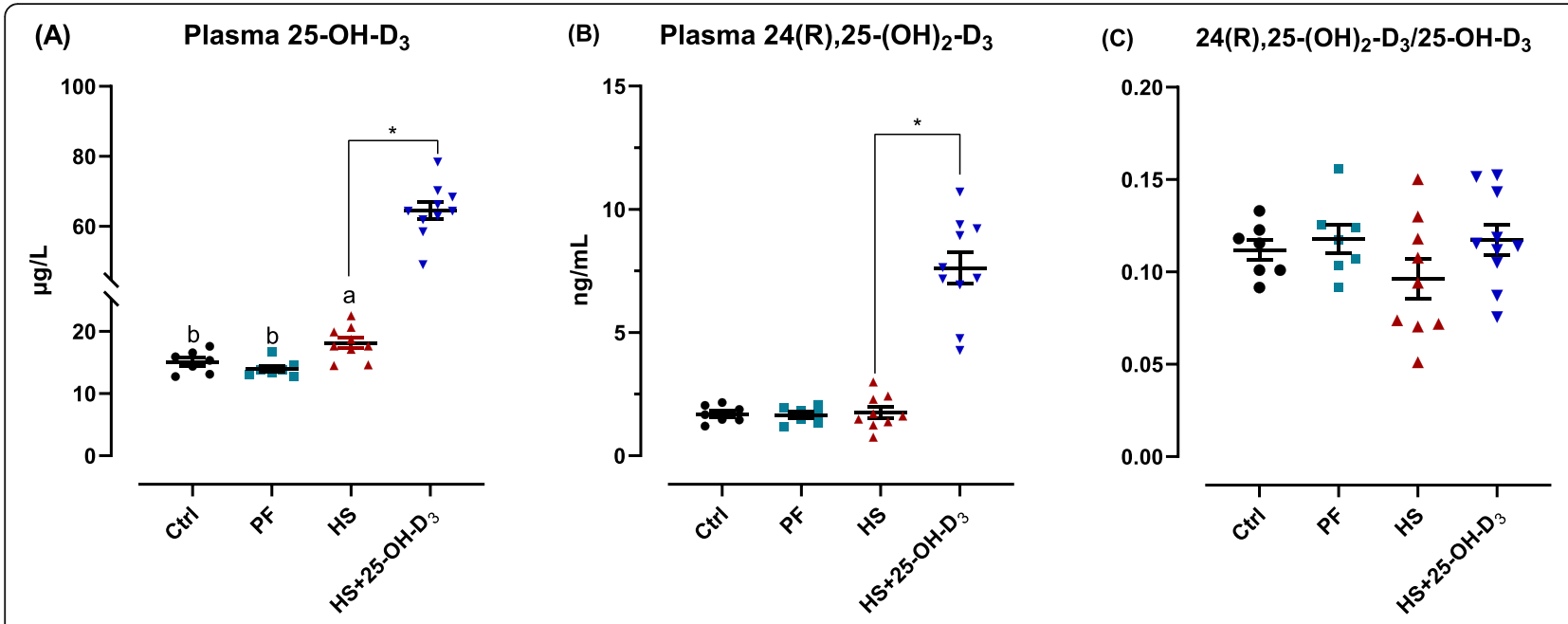

(D) Plasma Calcium and phosphorus
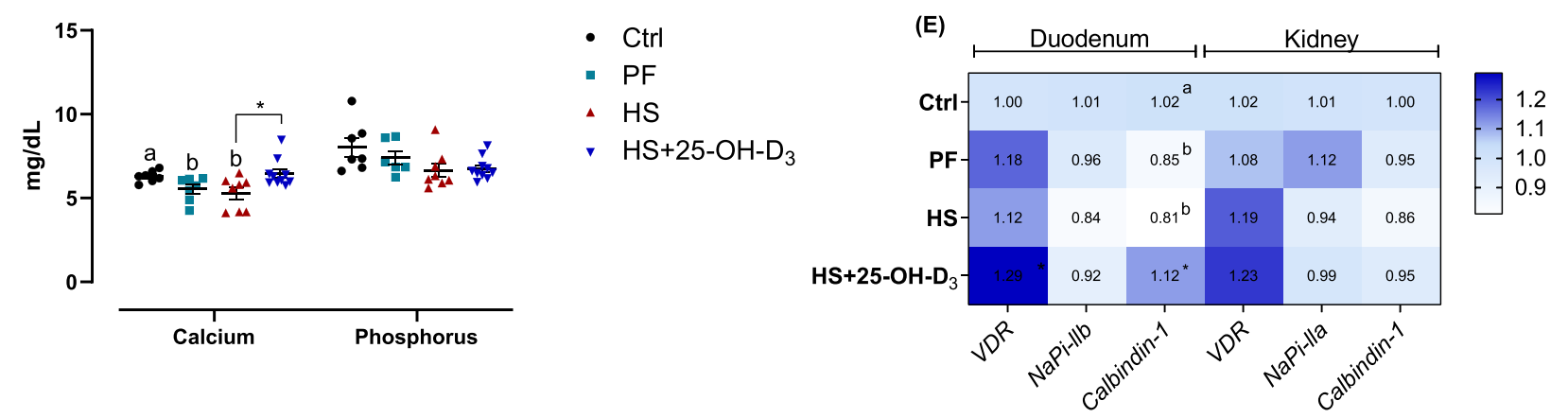

Fig. 2 Effect of $\mathrm{HS}$ and supplemental 25-OH-D $\mathrm{D}_{3}$ in broilers at d 39 on $\mathrm{Ca}$ and $\mathrm{P}$ homeostasis. Plasma $\mathbf{A}$ 25-OH-D $\mathrm{D}_{3}$, and $\mathbf{B}$ 24(R), 25-dihydroxyvitamin $\mathrm{D}_{3}\left(24(\mathrm{R}), 25-(\mathrm{OH})_{2}-\mathrm{D}_{3}\right), \mathbf{C}$ ratio $24(\mathrm{R}), 25-(\mathrm{OH})_{2}-\mathrm{D}_{3}$ to $25-\mathrm{OH}-\mathrm{D}_{3}$, and $\mathbf{D}$ calcium and phosphorus. mRNA abundance of $\mathbf{E}$ RT-PCR analysis for mRNA expression of vitamin D receptor (VDR), sodium-dependent phosphorus transport protein II (NaPi-Ilb) and calbindin-1 in duodenum, as well as VDR, NaPi-lla and calbindin-1 in kidney. Treatments Ctrl, PF and HS without common superscript are significantly different at $P<0.05 .{ }^{*}$ denotes significant difference between $\mathrm{HS}$ and $\mathrm{HS}+25-\mathrm{OH}-\mathrm{D}_{3}$ at $P<0.05$

among groups (Fig. 4E). The caecal microbiota in broilers was dominated by the Firmicutes and Bacteroidetes phyla. Specifically, Firmicutes levels were increased $(P<0.05)$ and Bacteroidetes levels (trend, $P=0.082$ ) were decreased in HS birds compared with Ctrl birds and a trend for similar changes in PF birds was seen (Fig. 4F, G). However, no differences were found between $\mathrm{HS}$ and $\mathrm{HS}+25-\mathrm{OH}-\mathrm{D}_{3}$ in either alpha diversity metrics or composition of the caecal microbiota at phylum level, though PCoA revealed a segregation between $\mathrm{HS}$ and $\mathrm{HS}+25-\mathrm{OH}-\mathrm{D}_{3}$ (Fig. 4D; $P>0.05$ ).

Total and individual SCFA contents of the caeca are also given in Table 3 . HS and dietary $25-\mathrm{OH}-\mathrm{D}_{3}$ failed to result in changes in terms of the levels of total SCFA, acetate, iso-valerate and valerate $(P>$ $0.05)$. However, heat exposure notably increased propionate, but decreased butyrate when compared with Ctrl group (both $P<0.05$ ), resulting in higher level of propionate than butyrate for the HS group $(P<0.05)$. Unexpectedly, iso-butyrate was increased by restricted feeding (PF) that was similar with HS group as compared to Ctrl group.

\section{Oxidative stress}

Heats stress and $25-(\mathrm{OH})-\mathrm{D}_{3}$ affects oxidative stress as shown in Table 4. MDA concentration in the ileal mucosa was higher in birds subjected to HS as compared with Ctrl and PF birds $(P<0.05)$. Similarly, plasma MDA concentration was increased by HS as compared with PF birds, but not with Ctrl birds $(P<0.05)$. GSH-Px activity in ileal mucosa and plasma were not different among Ctrl, PF and HS (both $P>0.05$ ), but SOD activity in ileal mucosa was decreased in HS compared with Ctrl or PF birds $(P<0.05)$. However, $25-\mathrm{OH}-\mathrm{D}_{3}$ treatment did not affect MDA content and antioxidant enzyme activities relative to HS broilers $(P>0.05)$. 


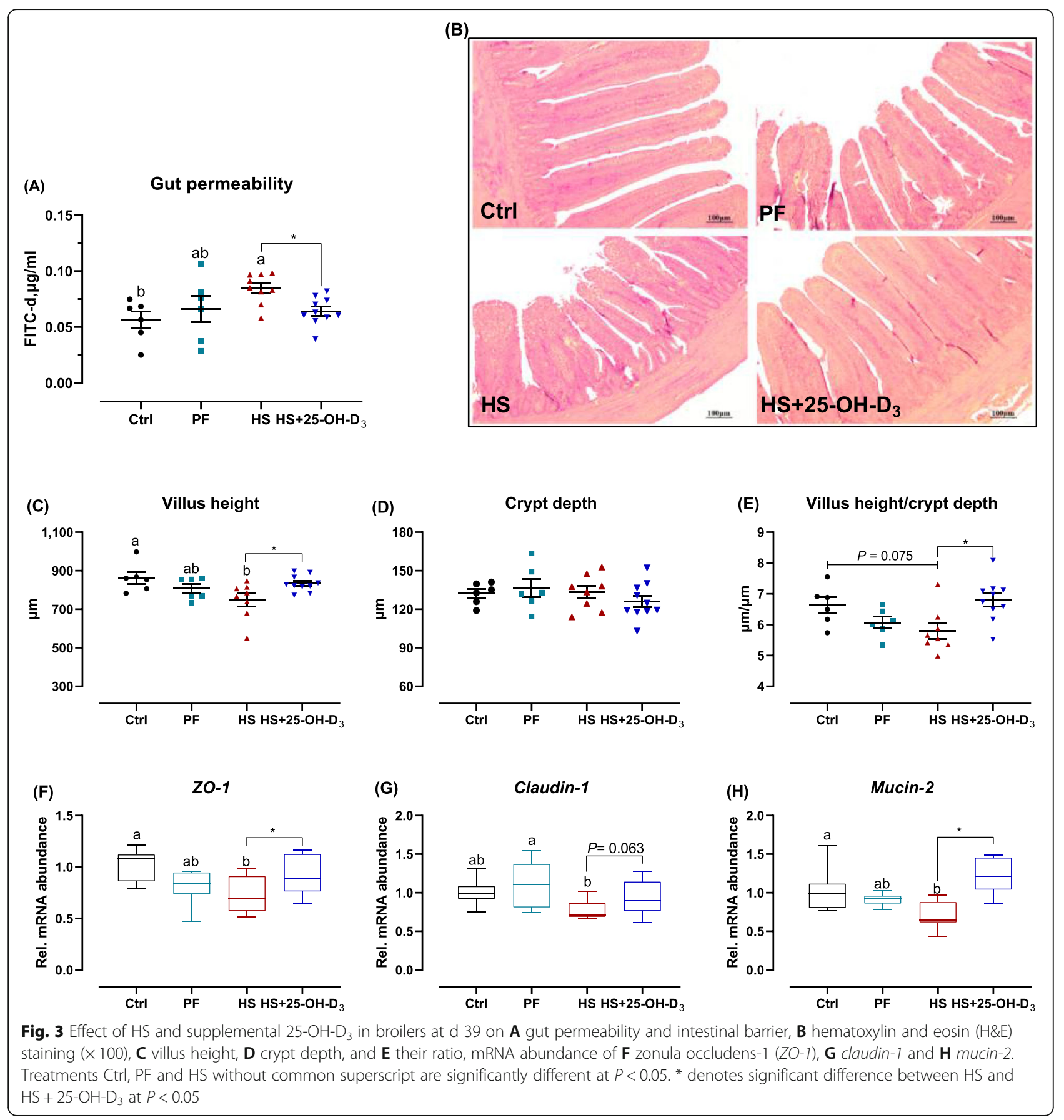

Immune status in ileum and bone marrow

In this study, HS reduced the relative weight of the thymus $(P<0.05)$, but it did not affect the relative weight of both the spleen and bursa (Fig. 5A, B). Hematological analysis of blood showed similar numbers of thrombocytes, heterophils, monocytes, lymphocytes and B-cells in Ctrl, PF and HS birds. A higher abundance of T-cells in HS birds as compared with Ctrl broilers was noticed but this did not reach significance (Fig. 5 C; $P>0.05$ ). As showed in Fig. 5D, the outcome of inflammation analysis revealed that the mRNA levels of proinflammatory factors, including $I L-1 \beta, I L-6$, and $T N F-\alpha$, were increased in the ileum of HS birds compared with Ctrl and/or PF broilers $(P<0.05)$. Transforming growth factor beta (TGF- $\beta$ ) mRNA expression, representing an antiinflammatory response, showed a trend to decrease in HS broilers $(P=0.087)$. In bone marrow, HS birds exhibited an increased expression of $I L-1 \beta, I L-6$, and TNF- $\alpha$ 


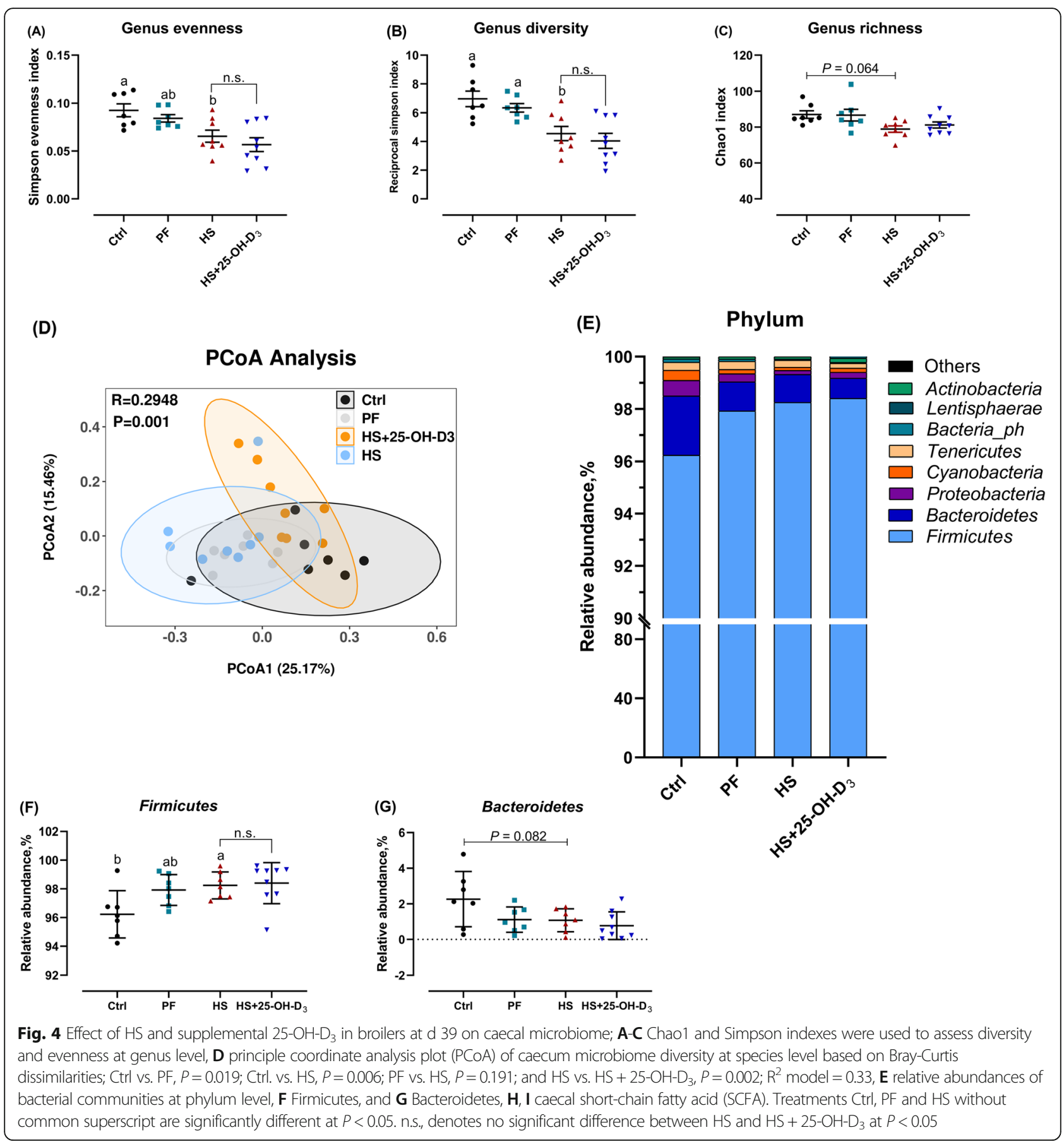

$(P<0.05)$, but similar TGF- $\beta$ mRNA level in bone marrow when compared to Ctrl or PF birds.

Furthermore, birds fed 25-OH- $\mathrm{D}_{3}$ diets displayed a substantial decrease in B-cells $(P<0.05)$ and T-cells $(P=0.052)$ compared to HS broilers (Fig. 5C). Abundances of pro-inflammatory factors were correspondingly modulated by dietary $25-\mathrm{OH}-\mathrm{D}_{3}$ treatment, i.e. $I L-1 \beta$ and TNF- $\alpha$ expression in ileum were remarkably suppressed by $25-\mathrm{OH}-\mathrm{D}_{3}$ supplementation while a trend for higher mRNA abundance of TGF- $\beta$ was seen $(P=0.078)$ (Fig. 5D). Similarly, the expressions of pro-inflammatory factors $I L-6$ and $T N F-\alpha$ were also decreased in bone marrow of $\mathrm{HS}+25-\mathrm{OH}-$ $\mathrm{D}_{3}$ compared with HS birds (Fig. 5D; $P<0.05$ ). However, the relative weight of immune organs and TGF$\beta$ mRNA expression in bone marrow did not change 
Table 3 Effect of HS and supplemental 25-hydroxycholecalciferol (25-OH-D $)$ on short-chain fatty acid (SCFA, $\mu \mathrm{mol} / \mathrm{g})$ in caeca of broilers at d 39

\begin{tabular}{|c|c|c|c|c|}
\hline Items & Ctrl & $\mathrm{PF}$ & HS & $\mathrm{HS}+25-\mathrm{OH}-\mathrm{D}_{3}$ \\
\hline Total SCFA & $117.03 \pm 3.71$ & $107.59 \pm 2.75$ & $115.48 \pm 3.21$ & $108.22 \pm 4.63$ \\
\hline Acetate & $71.08 \pm 1.17$ & $70.54 \pm 1.21$ & $72.13 \pm 0.67$ & $71.31 \pm 0.98$ \\
\hline Propionate & $9.77 \pm 0.72^{b}$ & $11.76 \pm 0.91^{\mathrm{ab}}$ & $13.82 \pm 1.05^{\mathrm{a}}$ & $12.48 \pm 0.88^{\text {n.s. }}$ \\
\hline Iso_butyrate & $0.69 \pm 0.14^{b}$ & $1.38 \pm 0.18^{\mathrm{a}}$ & $0.99 \pm 0.10^{\mathrm{ab}}$ & $1.01 \pm 0.06^{\text {n.s. }}$ \\
\hline Butyrate & $16.38 \pm 1.42^{\mathrm{a}}$ & $13.34 \pm 0.82^{\mathrm{ab}}$ & $10.76 \pm 0.67^{b}$ & $12.68 \pm 1.05^{\mathrm{n} . \mathrm{s}}$ \\
\hline Iso_ valerate & $0.97 \pm 0.19$ & $1.74 \pm 0.30$ & $1.11 \pm 0.12$ & $1.21 \pm 0.07$ \\
\hline Valerate & $1.11 \pm 0.08$ & $1.26 \pm 0.09$ & $1.19 \pm 0.09$ & $1.31 \pm 0.04$ \\
\hline
\end{tabular}

Data represent means with standard error;

Treatments Ctrl, $\mathrm{PF}$ and $\mathrm{HS}$ without common superscript are significantly different at $P<0.05$. n.s., denotes no significant difference between $\mathrm{HS}$ and $\mathrm{HS}+25-\mathrm{OH}-$ $D_{3}$ at $P<0.05$

by $25-\mathrm{OH}-\mathrm{D}_{3}$ supplementation during $\mathrm{HS}$ (Fig. 5 ; $P>$ $0.05)$.

\section{Bone resorption and formation}

Heat exposure and dietary 25- $\mathrm{OH}-\mathrm{D}_{3}$ administration significantly affected the bone resorption. Figure 6A shows that the circulatory level of CTx, that reflects bone resorption, was increased in HS compared with Ctrl or PF birds $(P<0.01)$, and then was depressed by dietary 25 $\mathrm{OH}-\mathrm{D}_{3}$ treatment $(P<0.05)$. As shown in Fig. 6B, TRAP-positive cells from HS birds were also distinctly increased, and supplementation of $25-\mathrm{OH}-\mathrm{D}_{3}$ reduced the number of TRAP-positive cells in bone sections. As far as osteoclastogenesis-related factors in bone, HS increased the expression level of RANKL $(P<0.01)$ and did not change osteoprotegerin (OPG) mRNA abundance, and thus notably increased $R A N K L$-to-OPG ratio when compared to Ctrl or PF groups $(P<0.05)$. Dietary $25-\mathrm{OH}-\mathrm{D}_{3}$ treatment elevated the expression level of $V D R$, and notably increased $O P G$ mRNA expression, and consequently decreased $R A N K L$-to-OPG ratio relative to HS broilers (Fig. $6 C ; P<0.05$ ). In addition, HS birds presented a significant increase mRNA expression level of cathepsin $K$ than those from Ctrl group $(P<0.05)$, and subsequently prominent decreased cathepsin $K$ mRNA level was also observed following dietary 25- $\mathrm{OH}-\mathrm{D}_{3}$ manipulation under $\mathrm{HS}$ (Fig. $6 \mathrm{C} ; \mathrm{P}<0.05$ ). HS exposure or $25-\mathrm{OH}-\mathrm{D}_{3}$ supplementation did not affect vacuolar $\mathrm{H}^{+}$-ATPases (VATPase) transcription (Fig. 6C).

No obvious differences in the serum ALP activity, an indicator of bone formation, and runt related transcription factor 2 (Runx2) mRNA level reflecting osteogenesis were observed (Fig. 6C, D; both $P>0.05$ ). Furthermore, with regard to the osteocyte-specific marker genes expression and when compared to Ctrl group, HS reduced the mRNA abundances of dentin matrix protein 1 (Dmp1) $(P<0.05)$, but the expression of sclerostin (Sost) and phosphate regulating endopeptidase homolog $\mathrm{x}$ linked (Phex) appears to be similar between Ctrl and HS (Fig. 6C). Next, the birds consuming the 25-OH- $\mathrm{D}_{3}$ diet displayed a significant increase in Sost, Dmp1, and Phex $(P=0.090)$ relative to HS broilers.

\section{Discussion}

Thermal environment has drawn greater attention to poultry producers because of its detrimental impacts, especially for meat-type poultry [1]. Exposure of birds to high ambient temperatures has shown to impair gut integrity and alter physiological homeostasis, such as

Table 4 Effect of HS and supplemental 25-hydroxycholecalciferol $\left(25-\mathrm{OH}-\mathrm{D}_{3}\right)$ on indices of oxidative status of broilers at $\mathrm{d} 39$

\begin{tabular}{|c|c|c|c|c|}
\hline Items & Ctrl & $\mathrm{PF}$ & HS & $\mathrm{HS}+25-\mathrm{OH}-\mathrm{D}_{3}$ \\
\hline \multicolumn{5}{|l|}{ Ileum } \\
\hline MDA, nmol/g & $15.57 \pm 0.66$ & $15.17 \pm 0.96$ & $17.8 \pm 0.42$ & $17.94 \pm 0.25$ \\
\hline GSH-Px, U/g & $4.66 \pm 0.51$ & $4.75 \pm 0.44$ & $4.97 \pm 0.25$ & $4.55 \pm 0.21$ \\
\hline $\mathrm{SOD}, \mathrm{U} / \mathrm{g}$ & $22.15 \pm 0.38$ & $20.28 \pm 1.28$ & $13.64 \pm 0.40$ & $13.82 \pm 1.53$ \\
\hline \multicolumn{5}{|l|}{ Plasma } \\
\hline $\mathrm{MDA}, \mathrm{nmol} / \mathrm{mL}$ & $16.25 \pm 0.52$ & $13.98 \pm 0.75$ & $19.45 \pm 0.94$ & $20.38 \pm 0.68$ \\
\hline GSH-Px, U/mL & $1.22 \pm 0.09$ & $1.16 \pm 0.08$ & $1.13 \pm 0.06$ & $1.08 \pm 0.07$ \\
\hline
\end{tabular}

Data represent means with standard error;

Treatments Ctrl, PF and HS without common superscript are significantly different at $P<0.05$. n.s., denotes no significant difference between $\mathrm{HS}$ and $\mathrm{HS}+25-\mathrm{OH}-$ $D_{3}$ at $P<0.05$;

MDA Malondialdehyde, GSH-Px Glutathione peroxidase, SOD Superoxide dismutase 


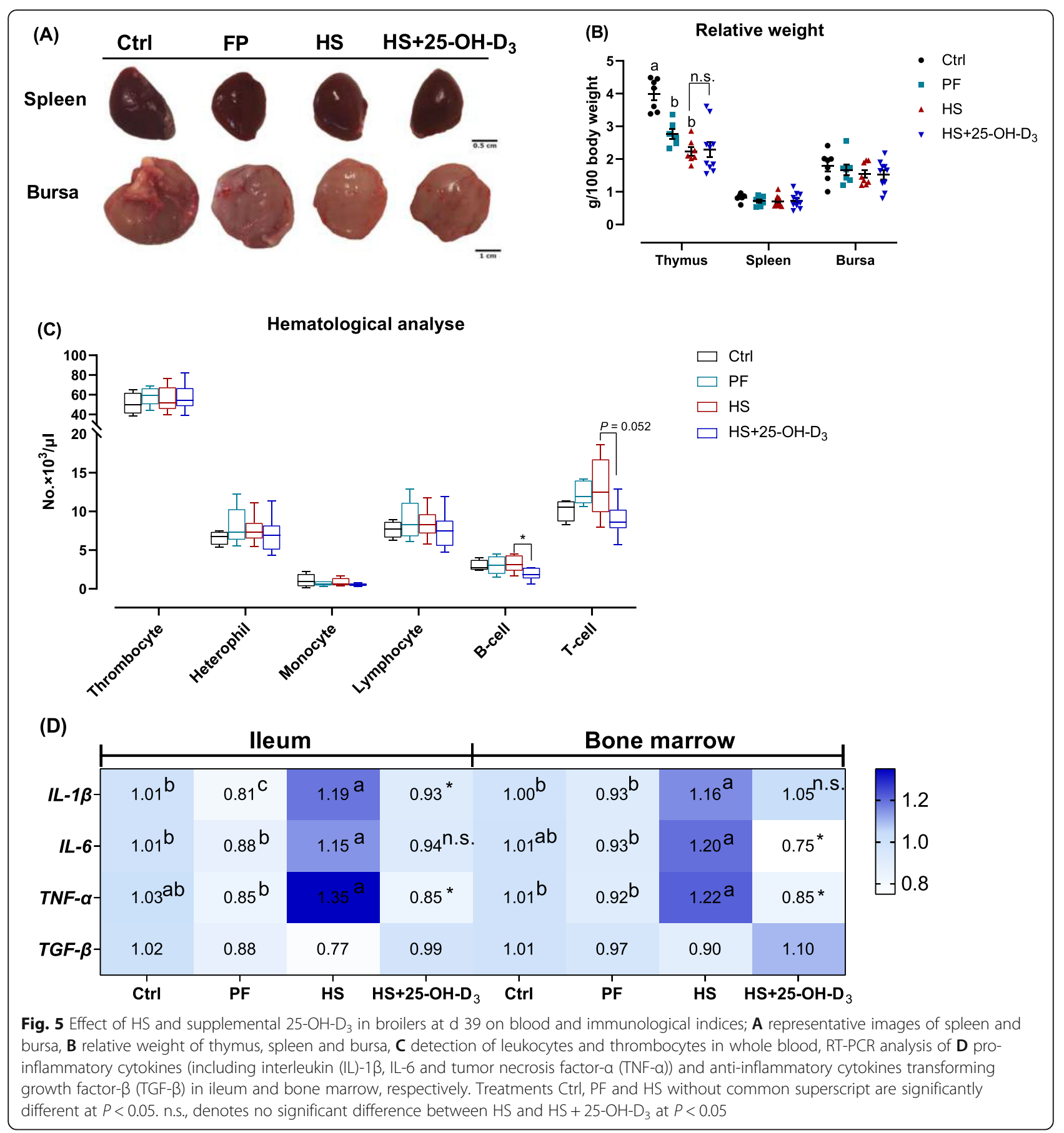

systemic immune dysregulation, endocrine and bone disorders, microbiota perturbation, which result in poor performance $[2,3,54]$. Similarly, the deleterious effects of HS were confirmed in the current study by decreased BW, FI and higher F: G. To accommodate heat dissipation, broilers can enhance their respiratory rate in the high temperature environment [55], which is illustrated by the higher panting frequency in our study. Moreover, rectal temperature and serum HSP70, both indicators of HS, were elevated by heat exposure. Altogether, this indicates that the chronic cyclic HS model was successfully established in this study. In our study we also included a pair feeding treatment (PF), i.e. birds were housed under thermoneutral conditions and fed restrictively in the finisher period following FI of HS birds. Thereby, the appropriate daily amount of feed was provided in three 


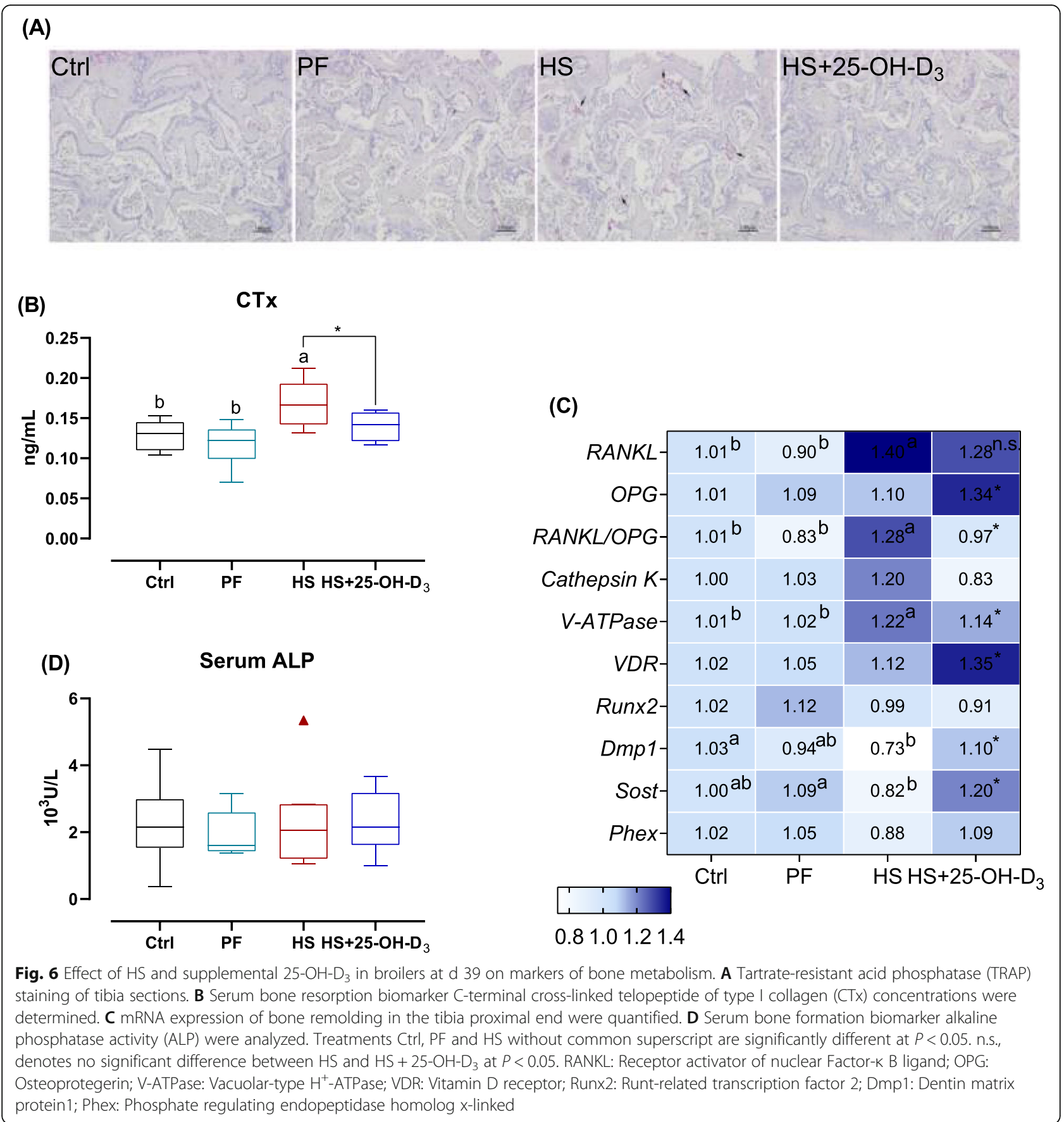

meals across the light hours of the day. PF was included to decipher whether HS effects are solely due to reduced FI. Indeed, FI of PF was equal to HS, and this corresponded to approximately $89 \%$ of ad libitum (Ctrl). For some indices, they were similar between Ctrl and PF, and both were different from HS, which suggests that HS effects are not associated with reduced FI; or vice versa, Ctrl distinctly differing from both $\mathrm{HS}$ and $\mathrm{PF}$ might imply that HS is deteriorating bird physiology in part due to reduced FI. Finally, for some variables, PF is simply intermediate, not different from Ctrl or HS while HS is unlike Ctrl. It is plausible that precise interpretation depends on the variable considered, thus not straightforward. However, we observed during feeding times of PF birds that severe aggression occurred, and feed consumption may have been largely variable for individual birds. Moreover, consuming three extensive meals in short time versus multiple smaller meals ad 


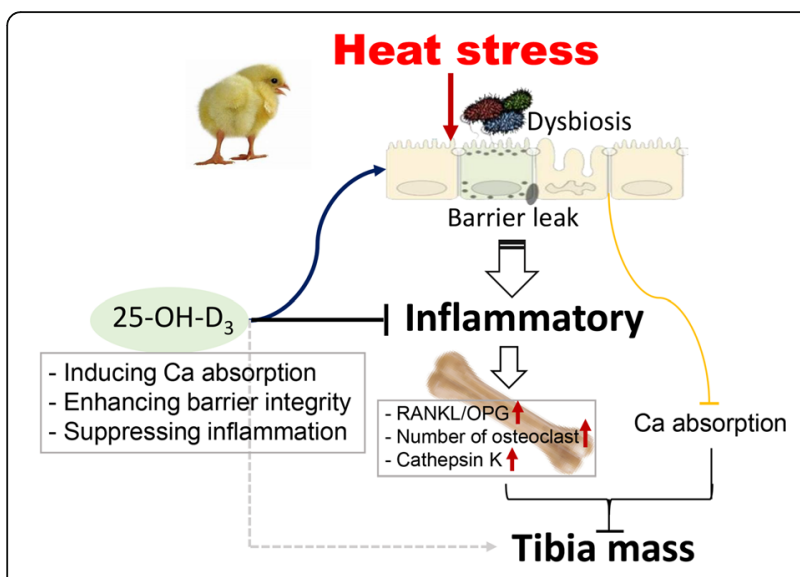

Fig. 7 Proposed mechanism for how $\mathrm{HS}$ and $25-\mathrm{OH}-\mathrm{D}_{3}$ regulate bone mass. HS leads to decreased bone mass caused by reduced $\mathrm{Ca}$ absorption, disturbed microbiota, increased systemic inflammation, and induces bone resorption evidenced by the increased frequency and activity of osteoclast in bone marrow. Furthermore, dietary 25$\mathrm{OH}-\mathrm{D}_{3}$ treatment promotes $\mathrm{Ca}$ absorption, enhances intestinal integrity, and exertes ant-inflammatory properties, and consequently reverses tibia quality deterioration induced by HS

libitum affects bird metabolism, and this might have confounded outcomes. Hereby, it is concluded that comparisons including PF should be interpreted cautiously.

Previous studies support a malignant role for HS in the regulation of bone health for birds. For example, imposing HS induced lower bone mass in broilers [2, 3], laying hens [4], and turkeys [5]. Negative effects of HS on tibia properties were also observed in this study. At the age of $39 \mathrm{~d}$, results of whole bone mechanical testing of tibia demonstrate that the bones from HS-birds were mechanically inferior in most variables tested, especially fracture load. In addition, AUC is a measure of the amount of energy required to cause bone fracture, and ductile bones require a larger amount of energy to failure than brittle bones [41]. In our study, the AUC of tibia from the Ctrl and PF group was greater than that of tibia from the HS group in spite of not reaching statistical significance, indicating that imposing HS impaired tibial strength and mechanical properties of broilers. Similar to the results obtained in the current experiment, previous studies on tibia from 42-d-old broilers have shown that HS notably reduced breaking strength compared with the group reared in thermo-neutral temperatures [56]. Increased ambient temperature and stocking density were also found to decrease the maximum elastic strength and ultimate strength of tibia in 126-d-old turkeys [5]. Bruno et al. reported that heat exposure in broilers strikingly reduced tibial length and width [57], while investigations of Jankowski et al. in turkeys showed that both tibial weight and length were depressed by increased environmental temperature [5]. The results of the present study consistently indicate that tibia from HS birds had slightly lower bone weight, length, and width than those of the Ctrl group. Furthermore, supplementation with $25-\mathrm{OH}-\mathrm{D}_{3}$ was found to effectively increase the mechanical properties of tibia in birds subjected to HS, and to some extent, alleviate the damage to gait score during HS.

Such different mechanical properties can be attributed to architectural features of the bones, to material composition and bone mass, or to a combination of these [58]. In the present study, unfavorable effects of HS on tibial mineral composition were visible when evaluating ash and density. In the HS group, both tibia ash and density were decreased compared with the Ctrl and PF group, indicating poorer tibial mass in birds exposed to HS. The negative effects of high ambient temperature on the tibia in broilers observed in this study are in accordance with some previous reports, in which heat exposure caused a meaningful reduction in the content of ash, $\mathrm{Ca}$, and $\mathrm{P}$ in broilers [2] and quails [59]. It should also be noted that $25-\mathrm{OH}-\mathrm{D}_{3}$ treatment caused positive changes in tibial mass as evidenced by apparent elevated bone ash, density, as well as the thickness of both trabecular and cortical bone, demonstrating that dietary supplementation with $25-\mathrm{OH}-\mathrm{D}_{3}$ can restore tibial mass induced by HS. Consistent with our findings, Sahin et al. showed that quails subjected to HS exhibited a significant decrease in tibia bone mineral density and tibial ash than those at thermoneutral environment, and these decreased bone parameters were linearly improved by 25$\mathrm{OH}-\mathrm{D}_{3}$ supplementation under HS [60]. These findings are in accordance with previous studies conducted in broilers [61, 62] and meat ducks [63].

To understand the mechanisms linking changes by HS and $25-\mathrm{OH}-\mathrm{D}_{3}$ to bone quality, it is useful to consider the three potential mechanisms: regulation of nutrient absorption [8], regulation of the intestinal barrier and immune system, and direct action on bone remodeling $[9,15]$. Recent studies have shown that HS in broilers [64] and high-yielding dairy cows [65] caused an apparent reduction in absorption of $\mathrm{Ca}$ and $\mathrm{P}$, along with the fact that HS compromises feed consumption. In the present study, the content of plasma Ca from the PF and HS groups were similar, both lower than Ctrl group, while a marginally lower P level was found in the plasma from the HS group, indicating that HS decreased $\mathrm{Ca}$ absorption and it was mainly associated with reduced food consumption. A compensatory increase in plasma 25$\mathrm{OH}-\mathrm{D}_{3}$ and a downregulated expression of calbindin-1 mRNA in duodenum but not kidney further illustrates that lower plasma $\mathrm{Ca}$ mainly resulted from decreased $\mathrm{Ca}$ absorption in duodenum and not from decreased reabsorption in kidney. Data on $25-\mathrm{OH}-\mathrm{D}_{3}$ and 24(R), 25- $(\mathrm{OH})_{2}-\mathrm{D}_{3}$ can also be used to evaluate the status of vitamin $\mathrm{D}$ from the perspective of the biological 
activity. 24(R), 25- $(\mathrm{OH})_{2}-\mathrm{D}_{3}$ is the first catabolite of 25$\mathrm{OH}-\mathrm{D}_{3}$ arising from its hydroxylation by cytochrome P24A1 and the ratio of $24(\mathrm{R}), 25-(\mathrm{OH})_{2}-\mathrm{D}_{3}$ to $25-\mathrm{OH}-$ $\mathrm{D}_{3}$ has been served as an index of vitamin $\mathrm{D}_{3}$ clearance [66]. In the present study, dietary $25-\mathrm{OH}-\mathrm{D}_{3}$ treatment heightened plasma $25-\mathrm{OH}-\mathrm{D}_{3}$ and $24(\mathrm{R}), 25-(\mathrm{OH})_{2}-\mathrm{D}_{3}$ concentrations but not pronouncedly changed the ratio of plasma $24(\mathrm{R}), 25-(\mathrm{OH})_{2}-\mathrm{D}_{3}$ to $25-\mathrm{OH}-\mathrm{D}_{3}$ indicating that catabolism of vitamin $\mathrm{D}_{3}$ was not induced response to dietary $25-\mathrm{OH}-\mathrm{D}_{3}$ supplementation. Moreover, dietary $25-\mathrm{OH}-\mathrm{D}_{3}$ treatment markedly heightened plasma $25-$ $\mathrm{OH}-\mathrm{D}_{3}$ concentration, which in turn has elevated plasma Ca level by inducing the mRNA expression of calbindin1 in duodenum of stressed-broilers. It is interesting to find out that supplemental $25-\mathrm{OH}-\mathrm{D}_{3}$ did not change plasma P level and the mRNA level of NaP-IIb and NaPIIa, both responsible for regulating $\mathrm{P}$ transport, in duodenum and kidney, respectively [67]. Comparable findings were reported in broilers fed $2.5-5 \mu \mathrm{g} / \mathrm{kg} 1 \alpha-$ $\mathrm{OH}-\mathrm{D}_{3}$. No significant differences in plasma $\mathrm{P}$ content and mRNA level of NaP-IIb and NaP-IIa were observed as compared with the birds fed control diets [68]. In addition, studies have also noticed that HS-induced morphological changes to the small intestine of broilers mainly consist of a shortened $\mathrm{V}$, deepened $\mathrm{C}$, and consequently reduced $\mathrm{V} / \mathrm{C}$ [69]. Inevitably, this will lead to substantial reduction of intestinal digestion and absorption surface. This is consistent with our present data on the ileum histomorphology of birds. Furthermore, the increases in $\mathrm{V}$ and $\mathrm{V} / \mathrm{C}$ by supplementation with 25$\mathrm{OH}-\mathrm{D}_{3}$ reflects enhanced digestion and absorption capacities of stressed-broilers [70]. Collectively, these results indicate that promoting $\mathrm{Ca}$ absorption and increasing absorption capacities of the small intestine through providing $25-\mathrm{OH}-\mathrm{D}_{3}$ can be crucial in alleviating the damage to bone mass due to HS-induced Ca deficiencies.

Impairment of gut integrity and regulation of systemic immune function might be another likely explanation for the differences in bone quality in the current study. It has been reported that HS directly impaired gut integrity and induced the activation of the innate immune system and systemic inflammation in bovine [10], rats [11], and laying hens [12]. The TJPs serves as the innate defense barrier, formed by ZO, claudins, occludin, and adherence junctions, along with the mucus that covers its surface. These protect the host against paracellular bacterial infiltration and penetration of toxic substrates [71]. Our results indicate lower ZO-1, claudin-1, and mucin-2 mRNA abundance in HS birds in line with findings in bovines [10] and broilers [72]. Subsequently this resulted in intestinal leakage, instructed by higher serum FITC-d level. These alterations of intestinal permeability can be related to bone health, supported by the fact that increased intestinal permeability observed in diseases, such as inflammatory bowel disease, is correlated with bone loss [73]. The high-molecular-weight polymer MDY is known to protect intestinal epithelial integrity against injury. A previous study pointed out that chickens infected with Salmonella benefit from MDY and do not loose trabecular bone as compared to untreated birds [74]. The administration of vitamin $\mathrm{D}_{3}$ was able to abolish the effects of LPS by restoring the expression of ZO-1 and claudin-2 [31], and had a protective effect against pepsin-trypsin-resistant gliadin induced tight junction injuries both in vitro and in vivo [32]. This underscores the importance of dietary $25-\mathrm{OH}-\mathrm{D}_{3}$ supplementation on the gut-bone signaling axis.

More important, in the current study, HS caused significant changes in microbial composition as evidenced by decreased genus evenness and diversity, as well as forming a distinct cluster that was separated from Ctrl. Relative abundance at the phylum levels manifested in substantial increases in Firmicutes, and an apparent decrease in Bacteroidetes, normally both predominant phyla in the caecum of broilers and laying hens. The results are consistent with previous reports in broilers [13, 14], but inconsistent with some earlier studies saying that HS had no effect on the phyla composition in the caecum of laying hens [75]. The reasons for this change in relative abundance at phylum level by HS is not clear but may be depend on animal species, feed, location and environment, as suggested by Stanley et al. [76]. A decrease in Bacteroidetes abundance has been associated with intestinal inflammation such as IBD [77]. Interestingly, reduced Firmicutes: Bacteroidetes ratio was linked with lower inflammatory state and declined bone loss of mice [78]. Moreover, several reports highlighted the immunomodulatory capacities of SCFA and provided a direct mechanistic link between the gut microbiota and bone [79]. Accordingly, recent studies suggested that direct treatment of mice with SCFA or feeding with a high-fiber diet was characterized by an increase in bone mass and prevented postmenopausal and inflammationinduced bone loss, along with increased serum SCFA levels and inhibition of osteoclast differentiation and bone resorption [80], indicating SCFA functioning as promoter of bone health. A recent review says that the fluctuation in bone properties were associated with alterations in SCFA levels [15]. In our study, total SCFA concentrations in the caecal content were comparable among Ctrl, PF and HS. However, and rather astonishingly, propionate production was favored over butyrate production when birds were heat-stressed, which was contrary to thermo-neutral raised birds and to what is commonly understood from caecal fermentations in broilers. Yan et al. deems that a direct effect of SCFA on bone resorption in vivo is unlikely as the circulating concentration of these molecules is lower than the 
concentration needed to affect osteoclast differentiation [81]. 25-OH- $\mathrm{D}_{3}$ supplementation did not affect either Firmicutes or Bacteroidetes abundance in the current study. This is in contrast to previous studies deemed that vitamin D could modify the relative abundance of bacteria by stimulating the release of antimicrobial peptides from macrophages [33]. Thus, whether dietary $25-\mathrm{OH}-\mathrm{D}_{3}$ addition is critical for the effects of gut microbiota on bone mass remains elusive, and more subtle effects may occur.

It is well-established that some factors such as HS that induce microbiota dysbiosis and disturbs intestinal barrier skew the gut towards a more pro-inflammatory state $[10,74]$, which is often characterized by increased levels of pro-inflammatory factors such as IL- 6 and TNF- $\alpha$. In this study, using the ileum pro-inflammatory (IL-1 $\beta$, IL6 and TNF- $\alpha$ ) and anti-inflammatory (TGF- $\beta$ ) factors as a marker of the balance between a pro- versus anti- inflammatory state, manifested that HS increased intestinal inflammation. Under conditions of impaired gut integrity, bacteria and their factors can translocate across the intestinal barrier to induce systemic inflammatory responses [73]. Heat-stressed quails exhibited higher serum TNF- $\alpha$ and C-reactive protein content [59]. Moreover, reduced relative weights of immune organs have been noticed in broilers under HS [2], which is confirmed by the results of the present study. It is wellestablished that inflammatory cytokines seem to have a direct role on bone remodeling via influencing the recruitment, maturation, proliferation, and activation of osteoclasts [82]. In this regard, rheumatoid arthritis proved to be a case for illustrating the relationship between inflammatory cytokines and bone metabolism. This autoimmune disease is characterized by inflammation with an increased expression of inflammatory cytokines such as TNF- $\alpha$, leading to severe bone destruction mediated by osteoclasts [83]. TNF- $\alpha$, which is secreted along with IL-1 from mononuclear cells, promotes osteoclastogenesis indirectly by stimulating RANKL expression, a facilitator of osteoclast differentiation, and enhancing RANKL binding to osteoclast precursors [84]. Mice with TNF- $\alpha$ induced arthritis were found to have increased circulation of osteoclast precursors. This was reversed by anti-TNF- $\alpha$ therapy and correlated with systemically increased TNF- $\alpha$ concentrations [85]. In addition, IL-6 is also another crucial inflammatory cytokine to stimulate osteoclast formation and function in vitro. IL-6 deficient mice were protected from a significant loss of bone mass together with an increase in bone turnover rates caused by estrogen depletion [86]. In line with these data, we found increased expression of $I L-1 \beta, I L-6$ and TNF- $\alpha$ in bone marrow of heat-stressed birds. Furthermore, the increased serum CTx content underscored that the bone resorption was enhanced in birds suffering from HS. Likely, this is a consequence of the increase in the number and activity of osteoclasts, i.e. apparent increases in TRAP-positive cells in the trabecular bone accompanied by upregulated mRNA level of cathepsin $K$, an enzyme secreted by mature osteoclasts to dissolve the organic components of bone in the process of bone resorption [87]. Specifically, RANKL binds to RANK that is expressed on the surface of osteoclast to induce osteoclast differentiation, whereas OPG acts as a decoy receptor by blocking the interaction of RANKL with its functional receptor RANK [88]. The higher RANKL-to-OPG ratio in HS birds than those in the Ctrl or PF broilers emphasizes the action of HS as inducer of osteoclast proliferation and differentiation. Furthermore, it is well known that B- and T-cells can foster profound changes in bone remodeling, despite the fact that the exact mechanisms are not well understood $[19,89]$. Studies have shown that germ-free mice have higher bone mass with reduced number of $\mathrm{CD} 4^{+} \mathrm{T}$ cells in bone marrow associated with a decreased expression of TNF- $\alpha$. This suggests that the gut microbiota is capable of shaping systemic immunity, and lower $\mathrm{CD} 4^{+} \mathrm{T}$ cells abundance is beneficial for bone mass [19]. However, disruption of the gut microbiota with antibiotics reduced $\mathrm{CD}_{2} \mathrm{O}^{+} \mathrm{B}$ and $\mathrm{CD}^{+} \mathrm{T}$ cell populations which was correlated with reduced whole-bone strength [89]. These inconsistent findings may be attributed to differences in animal age, sex, antibiotic usage, and genotype. Vitamin D showed anti-inflammatory functions [28]. Here, it decreased the number of B- and T-cells in blood, as well as depressed the expression of inflammatory factors, especially TNF- $\alpha$, in both ileal mucosa and bone marrow of broilers upon HS. It was also found that birds fed 25-OH- $\mathrm{D}_{3}$ under HS condition displayed a decreased frequency of TRAP-positive cells, serum CTx content, and cathepsin $K$ mRNA level. These data infer that $25-\mathrm{OH}-\mathrm{D}_{3}$ probably reduced bone resorption under HS by inhibiting the release of inflammatory factors that can promote osteoclastogenesis as a result of impaired intestinal integrity and/or dysbiosis. The final outcome is notably improved tibial mass. As a note, the current study did not include assessment of glucocorticoids, which usually is increased in birds under HS conditions [20], and can influence bone metabolism, leading to bone loss. Apart from reduction in bone formation through decreasing maturation and increasing apoptosis of osteoblasts, glucocorticoids may increase osteoclast maturation and activity, further contributing to increased bone resorption [20]. We therefore cannot rule out the possibility that the damage of tibia quality is not in part the result of glucocorticoids under HS.

Related to vitamin $\mathrm{D}$, we further cannot ignore the possibility that vitamin D directly targets bone related cells governing bone formation and resorption processes 
$[26,27]$. Our data clearly show that dietary supplementation with $25-\mathrm{OH}-\mathrm{D}_{3}$ markedly upregulated $V D R$ mRNA abundance in tibia. Therefore, it is possible that increased 25-OH-D ${ }_{3}$ binding VDR located at tibia promotes the production of OPG by osteoblasts which abolishes osteoclastogenesis and inhibits matured osteoclast's activity, evidenced by decreased cathepsin $K$ transcription, and consequently decreases in bone resorption. Such metabolic effects of $25-\mathrm{OH}-\mathrm{D}_{3}$ are in line with a previous report that vitamin $\mathrm{D}$ decreased osteoclast numbers by reducing the expression of OPG and decreasing the RANKL-to-OPG ratio in mice [90]. Additional analyses of bone formation markers indicate that it was regulated by $25-\mathrm{OH}-\mathrm{D}_{3}$. To be specific, early osteoblast development was unaffected by dietary 25$\mathrm{OH}-\mathrm{D}_{3}$ under HS. This is evidenced by the unchanged serum ALP concentration and Runx2 mRNA levels. However, an enhanced differentiated phenotype of bone cells was observed in birds fed $25-\mathrm{OH}-\mathrm{D}_{3}$ diets (upregulated Dmp1, Phex and Sost mRNA levels), which suggests the importance of $25-\mathrm{OH}-\mathrm{D}_{3}$ for the transition of osteoblasts to osteocytes. Although the anti-rachitic activity of vitamin D in vivo is well established, the impact of vitamin D on osteoblast differentiation is inconsistent. Some studies showed a stimulation of osteoblast differentiation and mineralization after vitamin $\mathrm{D}$ treatment [91, 92], but also an inhibition of osteoblast differentiation in mice was seen [90]. This discrepancy could be partly explained by the stage differentiation of osteoblast, $\mathrm{Ca}$ availability, or the dose of vitamin $\mathrm{D}$ used in these studies $[92,93]$. Past studies examining vitamin D/VDR signaling and osteoblast differentiation also found that that the early stages of osteoblast differentiation and mineral deposition are independent of the vitamin D/ VDR system, but it is particularly important during the late stages of osteoblast to osteocyte transition [94]. Thus, these results imply that the positive effect of dietary $25-\mathrm{OH}-\mathrm{D}_{3}$ on bone mass of birds suffering from HS is likely mediated by suppressing bone resorption but not by stimulating bone formation.

\section{Conclusion}

In this study, it was confirmed that HS has detrimental effects on bone health. We highlighted the importance of microbiota composition and intestinal barrier function in regulating bone quality. Disruption of intestinal integrity and dysbiosis by long-term exposure to high temperatures led to increased inflammation and bone resorption, and consequently impaired tibial quality. Furthermore, it was demonstrated that dietary supplementation with $25-\mathrm{OH}-\mathrm{D}_{3}$ was crucial for restoring bone health. Intestinal $\mathrm{Ca}$ absorption was enhanced and bone resorption reduced. These observations were associated with lower mRNA expression of inflammatory factors, and/or with direct modulation of osteoclast activity and maturation. Bone mass and strength was ameliorated by 25-OH- $\mathrm{D}_{3}$ when broilers were heat-stressed (Fig. 7).

\begin{abstract}
Abbreviations
25-OH-D $:$ : 25-hydroxycholecalciferol; ALP: Alkaline phosphatase; GSH-

Px: Glutathione peroxidase; HPLC-MSMS: Reversed-phase high pressure liquid

chromatography with tandem mass spectrometry; IL: Interleukin; micro-

CT: Micro computed tomography; RANKL: Receptor activator of nuclear

factor-K B ligand; SOD: Superoxide dismutase; TNF-a: Tumor necrosis factor

alpha; TRAP: Tartrate-resistant acid phosphatase; ZO-1: Zonula occludens 1
\end{abstract}

\section{Supplementary Information}

The online version contains supplementary material available at https://doi. org/10.1186/s40104-021-00627-6.

Additional file 1: Table S1. Composition and calculated nutrient content (as-fed). Table S2. Analysis of diet composition (as-fed). Table S3. The primers for quantitative real-time PCR.

\section{Authors' contributions}

$H Z, K Z$, and JM conceived and designed the experiments. HZ, MM, DJ, BT, $M B, D E, G T, I J$, and JM conducted the broiler study, collected and analyzed the samples. More specifically, BT and GD explored the microbiome by $16 \mathrm{~S}$ rRNA sequencing, MB and IJ ran the micro-CT scanning, whereas DG and DE did the processing of micro- $\mathrm{CT}$ data. $\mathrm{HZ}$ and MM conducted all other measurements. $\mathrm{HZ}, \mathrm{MM}$, and $\mathrm{JM}$ analyzed the data and wrote the first draft of the manuscript. All authors read and approved the final manuscript.

\section{Funding}

This work was supported by the China Scholarship Council (CSC, [2019]110) The support by DSM Nutritional Products (Basel, Switzerland) for the analysis of vitamin D3 and metabolites is well appreciated. The Ghent University Special Research Fund is acknowledged for the financial support to the UGCT Centre of Expertise (BOF.EXP.2017.0007).

\section{Declarations}

\section{Ethics approval and consent to participate}

The procedures of the animal experiment in this work were approved by the Ethics Committee of the Faculty of Veterinary Medicine, Ghent University (Belgium) for the humane care and use of animals in research (approval No. 2019-87).

Consent for publication

Not applicable.

\section{Competing interests}

The authors declare that they have no competing interests.

\section{Author details}

${ }^{1}$ Laboratory for Animal Nutrition and Animal Product Quality, Department of Animal Sciences and Aquatic Ecology, Ghent University, 9000 Ghent, Belgium. ${ }^{2}$ Key laboratory of Animal Disease-resistant Nutrition, Ministry of Education, Institute of Animal Nutrition, Sichuan Agricultural University, Ya'an 611130, Sichuan, China. ${ }^{3}$ Unit Molecular Immunology and Inflammation, VIB Center for Inflammation Research, Ghent University and Department of Rheumatology, Ghent University Hospital, 9000 Ghent, Belgium. ${ }^{4}$ Department of Food Sciences - Microbiology, University of Liège, 4000 Liège, Belgium. ${ }^{5}$ Ghent University Centre for X-ray Tomography (UGCT), Ghent University, 9000 Ghent, Belgium. ${ }^{6}$ Department of Physics and Astronomy, Radiation Physics Research Group, Ghent University, 9000 Ghent, Belgium.

Received: 19 April 2021 Accepted: 5 August 2021

Published online: 08 October 2021

\section{References}

1. Deeb N, Cahaner A. Genotype-by-environment interaction with broiler genotypes differing in growth rate. 3 . Growth rate and water consumption 
of broiler progeny from weight-selected versus nonselected parents under normal and high ambient temperatures. Poult Sci. 2002;81(3):293-301. https://doi.org/10.1093/ps/81.3.293.

2. Hosseini-Vashan SJ, Golian A, Yaghobfar A. Growth, immune, antioxidant, and bone responses of heat stress-exposed broilers fed diets supplemented with tomato pomace. Int J Biometeorol. 2016;60(8):1183-92. https://doi. org/10.1007/s00484-015-1112-9.

3. Yan FF, Mohammed AA, Murugesan GR, Cheng HW. Effects of a dietary synbiotic inclusion on bone health in broilers subjected to cyclic heat stress episodes. Poult Sci. 2019;98(3):1083-9. https://doi.org/10.3382/ps/pey508.

4. Koelkebeck KW, Harrison PC, Madindou T. effect of carbonated drinking water on production performance and bone characteristics of laying hens exposed to high environmental temperatures. Poult Sci. 1993;72(9):1800-3. https://doi.org/10.3382/ps.0721800.

5. Jankowski J, Mikulski D, Tatara MR, Krupski W. Effects of increased stocking density and heat stress on growth, performance, carcase characteristics and skeletal properties in turkeys. Vet Rec. 2015;176(1):21. https://doi.org/10.113 6/vr.102216

6. Rath NC, Huff GR, Huff WE, Balog JM. Factors regulating bone maturity and strength in poultry. Poult Sci. 2000;79(7):1024-32. https://doi.org/10.1093/ps/ 79.7.1024.

7. Reiter K, Bessei W. Effect of locomotor activity on leg disorder in fattening chicken. Berliner und Munchener tierarztliche Wochenschrift. 2009;122(7-8): 264-70

8. Wiernusz CJ, Teeter RG. Acclimation effects on fed and fasted broiler thermobalance during thermoneutral and high ambient temperature exposure. Br Poult Sci. 1996;37(3):677-87. https://doi.org/10.1080/00071 669608417897.

9. D'Amelio P, Sassi F. Gut microbiota, immune system, and bone. Calcif Tissue Int. 2018;102(4):415-25. https://doi.org/10.1007/s00223-017-0331-y.

10. Koch F, Thom U, Albrecht E, Weikard R, Nolte W, Kuhla B, et al. Heat stress directly impairs gut integrity and recruits distinct immune cell populations into the bovine intestine. Proc Natl Acad Sci U S A. 2019;116(21):10333-8. https://doi.org/10.1073/pnas.1820130116.

11. Hall DM, Buettner GR, Oberley LW, Xu L, Matthes RD, Gisolfi CV. Mechanisms of circulatory and intestinal barrier dysfunction during whole body hyperthermia. Am J Physiol Heart Circ Physiol. 2001;280(2):H509-21. https:// doi.org/10.1152/ajpheart.2001.280.2.H509.

12. Zhu L, Liao R, Wu N, Zhu G, Yang C. Heat stress mediates changes in fecal microbiome and functional pathways of laying hens. Appl Microbiol Biotechnol. 2019;103(1):461-72. https://doi.org/10.1007/s00253-018-9465-8.

13. Shi D, Bai L, Qu Q, Zhou S, Yang M, Guo S, et al. Impact of gut microbiota sturcture in heat-stressed broilers. Poult Sci. 2019;98(6):2405-13. https://doi. org/10.3382/ps/pez026

14. Wang XJ, Feng JH, Zhang MH, Li XM, Ma DD, Chang SS. Effects of high ambient temperature on the community structure and composition of ileal microbiome of broilers. Poult Sci. 2018;97(6):2153-8. https://doi.org/10.3382/ ps/pey032.

15. Chen YC, Greenbaum J, Shen H, Deng HW. Association between gut microbiota and bone health: potential mechanisms and prospective. J Clin Endocrinol Metab. 2017;102(10):3635-46. https://doi.org/10.1210/jc.201700513.

16. Schwarzer M, Makki K, Storelli G, Machuca-Gayet I, Srutkova D, Hermanova P, et al. Lactobacillus plantarum strain maintains growth of infant mice during chronic undernutrition. Science. 2016;351(6275):854-7. https://doi.org/10.112 6/science.aad8588.

17. Yan J, Charles JF. Gut microbiome and bone: to build, destroy, or both? Curr Osteoporos Rep. 2017;15(4):376-84. https://doi.org/10.1007/s11914017-0382-z.

18. Ohlsson C, Nigro G, Boneca IG, Backhed F, Sansonetti P, Sjogren K. Regulation of bone mass by the gut microbiota is dependent on NOD1 and NOD2 signaling. Cell Immunol. 2017;317:55-8. https://doi.org/10.1016/j. cellimm.2017.05.003.

19. Sjogren K, Engdahl C, Henning P, Lerner UH, Tremaroli V, Lagerquist MK, et al. The gut microbiota regulates bone mass in mice. J Bone Miner Res. 2012;27(6):1357-67. https://doi.org/10.1002/jbmr.1588.

20. Henneicke H, Gasparini SJ, Brennan-Speranza TC, Zhou H, Seibel MJ. Glucocorticoids and bone: local effects and systemic implications. Trends Endocrinol Metab. 2014;25(4):197-211. https://doi.org/10.1016/j. tem.2013.12.006.
21. Wauquier F, Leotoing L, Coxam V, Guicheux J, Wittrant Y. Oxidative stress in bone remodelling and disease. Trends Mol Med. 2009;15(10):468-77. https:// doi.org/10.1016/j.molmed.2009.08.004

22. Sun $Z W$, Yan $L, G$ YY, Zhao JP, Lin $H$, Guo YM. Increasing dietary vitamin $D_{3}$ improves the walking ability and welfare status of broiler chickens reared at high stocking densities. Poult Sci. 2013;92(12):3071-9. https://doi.org/10.33 82/ps.2013-03278.

23. Jiang $S$, Jiang $Z$, Yang $K$, Chen $F$, Zheng $C$, Wang L. Dietary vitamin $D_{3}$ requirement of Chinese yellow-feathered broilers. Poult Sci. 2015;94(9):221020. https://doi.org/10.3382/ps/pev163.

24. Khan SH, Shahid R, Mian AA, Sardar R, Anjum MA. Effect of the level of cholecalciferol supplementation of broiler diets on the performance and tibial dyschondroplasia. J Anim Physiol Anim Nutr (Berl). 2010;94(5):584-93. https://doi.org/10.1111/j.1439-0396.2009.00943.x.

25. Christakos S, Dhawan P, Porta A, Mady LJ, Seth T. Vitamin D and intestinal calcium absorption. Mol Cell Endocrinol. 2011;347(1-2):25-9.

26. Nakamichi Y, Udagawa N, Suda T, Takahashi N. Mechanisms involved in bone resorption regulated by vitamin D. J Steroid Biochem Mol Biol. 2018; 177:70-6. https://doi.org/10.1016/j.jsbmb.2017.11.005.

27. van Driel $\mathrm{M}$, van Leeuwen J. Vitamin $\mathrm{D}$ endocrinology of bone mineralization. Mol Cell Endocrinol. 2017:453:46-51. https://doi.org/10.1016/ j.mce.2017.06.008.

28. Waterhouse M, Hope B, Krause L, Morrison M, Protani MM, Zakrzewski M, et al. Vitamin $D$ and the gut microbiome: a systematic review of in vivo studies. Eur J Nutr. 2018;58(7):2895-910.

29. Sepidarkish M, Farsi F, Akbari-Fakhrabadi M, Namazi N, Almasi-Hashiani A, Maleki Hagiagha A, et al. The effect of vitamin D supplementation on oxidative stress parameters: a systematic review and meta-analysis of clinical trials. Pharmacol Res. 2019;139:141-52. https://doi.org/10.1016/j. phrs.2018.11.011.

30. Domazetovic V, Marcucci G, lantomasi T, Brandi ML, Vincenzini MT. Oxidative stress in bone remodeling: role of antioxidants. Clin Cases Miner Bone Metab. 2017;14(2):209-16. https://doi.org/10.11138/ccmbm/2 017.14.1.209.

31. Lee C, Lau E, Chusilp S, Filler R, Li B, Zhu H, et al. Protective effects of vitamin D against injury in intestinal epithelium. Pediatr Surg Int. 2019; 35(12):1395-401. https://doi.org/10.1007/s00383-019-04586-y.

32. Dong $S$, Singh TP, Wei $X$, Yao $H$, Wang $H$. Protective effect of 1,25-dihydroxy vitamin $\mathrm{D}_{3}$ on pepsin-trypsin-resistant gliadin-induced tight junction injuries. Dig Dis Sci. 2018;63(1):92-104. https://doi.org/10.1007/s10620-017-4738-0.

33. Guo C, Gombart AF. The antibiotic effects of vitamin D. Endocr Metab Immune Disord Drug Targets. 2014;14(4):255-66. https://doi.org/10.2174/1 871530314666140709085159.

34. Jain SK, Micinski D. Vitamin D upregulates glutamate cysteine ligase and glutathione reductase, and GSH formation, and decreases ROS and MCP-1 and IL-8 secretion in high-glucose exposed U937 monocytes. Biochem Biophys Res Commun. 2013;437(1):7-11. https://doi.org/10.1016/j.bbrc.2013. 06.004.

35. Han JC, Chen GH, Wang JG, Zhang JL, Qu HX, Zhang CM, et al. Evaluation of relative bioavailability of 25 -hydroxycholecalciferol to cholecalciferol for broiler chickens. Asian-Australas J Anim Sci. 2016;29(8):1145-51. https://doi. org/10.5713/ajas.15.0553.

36. Spranghers T, Michiels J, Vrancx J, Ovyn A, Eeckhout M, De Clerca P, et al. Gut antimicrobial effects and nutritional value of black soldier fly (Hermetia illucens L.) prepupae for weaned piglets. Anim Feed Sci Tech. 2018;235:33-42.

37. Majdeddin M, Braun U, Lemme A, Golian A, Kermanshahi H, De Smet S, et al. Guanidinoacetic acid supplementation improves feed conversion in broilers subjected to heat stress associated with muscle creatine loading and arginine sparing. Poult Sci. 2020;99(9):4442-53. https://doi.org/10.1016/j. psj.2020.05.023.

38. Knowles TG, Kestin SC, Haslam SM, Brown SN, Green LE, Butterworth A, et al. Leg disorders in broiler chickens: prevalence, risk factors and prevention. PLoS One. 2008;3(2):e1545. https://doi.org/10.1371/journal.pone. 0001545.

39. Baxter MFA, Merino-Guzman R, Latorre JD, Mahaffey BD, Yang Y, Teague KD, et al. Optimizing fluorescein isothiocyanate dextran measurement as a biomarker in a 24-h feed restriction model to induce gut permeability in broiler chickens. Front Vet Sci. 2017;4:56. https://doi.org/10.3389/fvets.2017. 00056. 
40. Seliger C, Schaerer B, Kohn M, Pendl H, Weigend S, Kaspers B, et al. A rapid high-precision flow cytometry based technique for total white blood cell counting in chickens. Vet Immunol Immunopathol. 2012;145(1-2):86-99.

41. Turner CH. Bone strength: current concepts. Ann N Y Acad Sci. 2006;1068(1): 429-46. https://doi.org/10.1196/annals.1346.039.

42. Masschaele B, Dierick M, Loo DV, Boone MN, Brabant L, Pauwels E, et al. HECTOR: a 240kV micro-CT setup optimized for research. J Phys Conf Ser. 2013;463:012012. https://doi.org/10.1088/1742-6596/463/1/012012.

43. Vlassenbroeck J, Dierick M, Masschaele B, Cnudde V, Van Hoorebeke L, Jacobs P. Software tools for quantification of X-ray microtomography at the UGCT. Nuclear Instruments Methods Phys Res Sec A. 2007;580(1):442-5. https://doi.org/10.1016/j.nima.2007.05.073.

44. Buie HR, Campbell GM, Klinck RJ, MacNeil JA, Boyd SK. Automatic segmentation of cortical and trabecular compartments based on a dual threshold technique for in vivo micro-CT bone analysis. Bone. 2007:41(4): 505-15. https://doi.org/10.1016/j.bone.2007.07.007.

45. Doube M, Kłosowski MM, Arganda-Carreras I, Cordelières FP, Dougherty RP, Jackson JS, et al. BoneJ: free and extensible bone image analysis in ImageJ. Bone. 2010;47(6):1076-9. https://doi.org/10.1016/j.bone.2010.08.023.

46. van Nevel CJ, Decuypere JA, Dierick N, Molly K. The influence of Lentinus edodes (shiitake mushroom) preparations on bacteriological and morphological aspects of the small intestine in piglets. Archiv fur Tierernahrung. 2003;57(6):399-412. https://doi.org/10.1080/0003942032000161054.

47. Grotto D, Santa Maria LD, Boeira S, Valentini J, Charão MF, Moro AM, et al. Rapid quantification of malondialdehyde in plasma by high performance liquid chromatography-visible detection. J Pharm Biomed Anal. 2007;43(2): 619-24. https://doi.org/10.1016/j.jpba.2006.07.030.

48. Hernández P, Zomeño L, Ariño B, Blasco A. Antioxidant, lipolytic and proteolytic enzyme activities in pork meat from different genotypes. Meat Sci. 2004;66(3):525-9. https://doi.org/10.1016/S0309-1740(03)00155-4.

49. Marklund S, Marklund G. Involvement of the superoxide anion radical in the autoxidation of pyrogallol and a convenient assay for superoxide dismutase. Eur J Biochem. 1974;47(3):469-74. https://doi.org/10.1111/j.1432-1033.1974. tb03714.x

50. Schloss PD, Westcott SL, Ryabin T, Hall JR, Hartmann M, Hollister EB, et al. Introducing mothur: open-source, platform-independent, communitysupported software for describing and comparing microbial communities. Appl Environ Microbiol. 2009;75(23):7537-41. https://doi.org/10.1128/AEM.01 541-09.

51. Rognes T, Flouri T, Nichols B, Quince C, Mahé F. VSEARCH: a versatile open source tool for metagenomics. PeerJ. 2016;4:e2584. https://doi.org/10.7717/ peerj.2584.

52. Quast C, Pruesse E, Yilmaz P, Gerken J, Schweer T, Yarza P, et al. The SILVA ribosomal RNA gene database project: improved data processing and webbased tools. Nucleic Acids Res. 2013;41(Database issue):D590-6. https://doi. org/10.1093/nar/gks1219.

53. Castro-Montoya J, De Campeneere S, Van Ranst G, Fievez V. Interactions between methane mitigation additives and basal substrates on in vitro methane and VFA production. Anim Feed Sci Tech. 2012;176(1-4):47-60.

54. Quinteiro-Filho WM, Rodrigues MV, Ribeiro A, Ferraz-de-Paula V, Pinheiro $M L$, Sá $L R$, et al. Acute heat stress impairs performance parameters and induces mild intestinal enteritis in broiler chickens: role of acute hypothalamic-pituitary-adrenal axis activation. J Anim Sci. 2012;90(6):198694. https://doi.org/10.2527/jas.2011-3949.

55. Lara $L$, Rostagno MH. Impact of heat stree on poultry production. Animals. 2013;3(2):356-69. https://doi.org/10.3390/ani3020356.

56. Ruff J, Barros TL, Tellez G Jr, Blankenship J, Lester H, Graham BD, et al. Research note: evaluation of a heat stress model to induce gastrointestinal leakage in broiler chickens. Poult Sci. 2020;99(3):1687-92. https://doi.org/10.1 016/j.psj.2019.10.075

57. Bruno LD, Furlan RL, Malheiros EB, Macari M. Influence of early quantitative food restriction on long bone growth at different environmental temperatures in broiler chickens. Br Poult Sci. 2000;41(4):389-94. https://doi. org/10.1080/713654955.

58. Sharir A, Barak MM, Shahar R. Whole bone mechanics and mechanical testing. Vet J. 2008;177(1):8-17. https://doi.org/10.1016/j.tvjl.2007.09.012.

59. Sahin K, Onderci M, Sahin N, Balci TA, Gursu MF, Juturu V, et al. Dietary arginine silicate inositol complex improves bone mineralization in quail. Poult Sci. 2006;85(3):486-92. https://doi.org/10.1093/ps/85.3.486.

60. Sahin N, Balci TA, Kucuk O, Smith MO, Sahin K. Effects of 25hydroxycholecalciferol and soy isoflavones supplementation on bone mineralisation of quail. Br Poult Sci. 2009;50(6):709-15. https://doi.org/10.1 080/00071660903261944.

61. Santiago M, David S, Alexandra N, Eduardo A, Jimmy Q. Effect of 25hydroxycholecalciferol $\left(25-\mathrm{OH}-\mathrm{D}_{3}\right)$ on productive performance and bone mineralization in broiler. J Anim Sci. 2016;6(3):180-4.

62. Wideman RF Jr, Blankenship J, Pevzner IY, Turner BJ. Efficacy of 25-OH vitamin $\mathrm{D}_{3}$ prophylactic administration for reducing lameness in broilers grown on wire flooring. Poult Sci. 2015;94(8):1821-7. https://doi.org/10.33 82/ps/pev160

63. Zhang HY, Zeng QF, Bai SP, Wang JP, Ding XM, Xuan Y, et al. Effect of dietary 25-hydroxycholecalciferol on the sternal mass of meat ducks under different vitamin regimens. Poult Sci. 2020;99(3):1241-53. https://doi.org/10.1 016/j.psj.2019.10.068

64. Cardoso EF, Donzele JL, de Oliveira Donzele RFM, Sufiate BL, Silva AD, Tizziani T. Non-phytate phosphorus requirement for broilers from 8 to 21 days of age under heat stress conditions. Trop Anim Health Prod. 2018; 50(2):317-25. https://doi.org/10.1007/s11250-017-1434-1.

65. Kamiya $Y$, Kamiya M, Tanaka $M$. The effect of high ambient temperature on $\mathrm{ca}, \mathrm{P}$ and $\mathrm{mg}$ balance and bone turnover in high-yielding dairy cows. Anim Sci J. 2010;81(4):482-6. https://doi.org/10.1111/j.1740-0929.2010.00761.x.

66. Wagner D, Hanwell HE, Schnabl K, Yazdanpanah M, Kimball S, Fu L, et al. The ratio of serum 24,25-dihydroxyvitamin D (3) to 25-hydroxyvitamin D (3) is predictive of 25 -hydroxyvitamin D (3) response to vitamin D (3) supplementation. J Steroid Biochem Mol Biol. 2011;126(3-5):72-7.

67. Murer H, Forster I, Biber J. The sodium phosphate cotransporter family SLC34. Pflugers Arch. 2004;447(5):763-7. https://doi.org/10.1007/s00424003-1072-5.

68. Han JC, Wang JG, Chen GH, Zhang JL, Zhang N, Qu HX, et al. 1alphahydroxycholecalciferol improves the growth performance and up-regulates the mRNA expression of vitamin D receptor in the small intestine and kidney of broiler chickens. Poult Sci. 2018;97(4):1263-70. https://doi.org/1 0.3382/ps/pex423.

69. Liu L, Fu C, Yan M, Xie H, Li S, Yu Q, et al. Resveratrol modulates intestinal morphology and HSP70/90, NF-kappaB and EGF expression in the jejunal mucosa of black-boned chickens on exposure to circular heat stress. Food Funct. 2016;7(3):1329-38. https://doi.org/10.1039/C5FO01338K.

70. Zhao Y, Yu B, Mao X, He J, Huang Z, Zheng P, et al. Dietary vitamin D supplementation attenuates immune responses of pigs challenged with rotavirus potentially through the retinoic acid-inducible gene I signalling pathway. $\mathrm{Br}$ J Nutr. 2014;112(3):381-9. https://doi.org/10.1017/S000711451400097X.

71. Walters JR. Cell and molecular biology of the small intestine: new insights into differentiation, growth and repair. Curr Opin Gastroenterol. 2004;20(2): 70-6. https://doi.org/10.1097/00001574-200403000-00004.

72. Zhang $C$, Zhao XH, Yang $L$, Chen XY, Jiang RS, Jin SH, et al. Resveratrol alleviates heat stress-induced impairment of intestinal morphology, microflora, and barrier integrity in broilers. Poult Sci. 2017;96(12):4325-32. https://doi.org/10.3382/ps/pex266.

73. Bianchi ML. Inflammatory bowel diseases, celiac disease, and bone. Arch Biochem Biophys. 2010;503(1):54-65. https://doi.org/10.1016/j.abb.2010.06.026.

74. Irwin R, Raehtz S, Parameswaran N, McCabe LR. Intestinal inflammation without weight loss decreases bone density and growth. Am J Physiol Regul Integr Comp Physiol. 2016;311(6):R1149-57. https://doi.org/10.1152/a jpregu.00051.2016.

75. Xing S, Wang $X$, Diao $H$, Zhang M, Zhou Y, Feng J. Changes in the cecal microbiota of laying hens during heat stress is mainly associated with reduced feed intake. Poult Sci. 2019;98(11):5257-64. https://doi.org/10.3382/ ps/pez440.

76. Stanley D, Geier MS, Denman SE, Haring VR, Crowley TM, Hughes RJ, et al. Identification of chicken intestinal microbiota correlated with the efficiency of energy extraction from feed. Vet Microbiol. 2013;164(1-2):85-92.

77. Schirmer M, Franzosa EA, Lloyd-Price J, Mclver LJ, Schwager R, Poon TW et al. Dynamics of metatranscription in the inflammatory bowel disease gut microbiome. Nat Microbiol. 2018;3(3):337-46. https://doi.org/10.1038/s41 564-017-0089-z.

78. Schepper JD, Collins FL, Rios-Arce ND, Raehtz S, Schaefer L, Gardinier JD, et al. Probiotic lactobacillus reuteri prevents postantibiotic bone loss by reducing intestinal dysbiosis and preventing barrier disruption. J Bone Miner Res. 2019;34(4):681-98. https://doi.org/10.1002/jbmr.3635.

79. Zaiss MM, Jones RM, Schett G, Pacifici R. The gut-bone axis: how bacterial metabolites bridge the distance. J Clin Invest. 2019;129(8):3018-28. https:// doi.org/10.1172/JCl128521 
80. Lucas S, Omata Y, Hofmann J, Böttcher M, lljazovic A, Sarter K, et al. Shortchain fatty acids regulate systemic bone mass and protect from pathological bone loss. Nat Commun. 2018;9(1):55. https://doi.org/10.1038/ s41467-017-02490-4

81. Yan J, Takakura A, Zandi-Nejad K, Charles JF. Mechanisms of gut microbiotamediated bone remodeling. Gut Microbes. 2018;9(1):84-92. https://doi.org/1 0.1080/19490976.2017.1371893.

82. Horowitz MC. Cytokines and estrogen in bone: anti-osteoporotic effects. Science. 1993;260(5108):626-7. https://doi.org/10.1126/science.8480174.

83. Sato K, Takayanagi H. Osteoclasts, rheumatoid arthritis, and osteoimmunology. Curr Opin Rheumatol. 2006;18(4):419-26. https://doi. org/10.1097/01.bor.0000231912.24740.a5.

84. Lam J, Takeshita S, Barker JE, Kanagawa O, Ross FP, Teitelbaum SL. TNFalpha induces osteoclastogenesis by direct stimulation of macrophages exposed to permissive levels of RANK ligand. J Clin Invest. 2000;106(12): 1481-8. https://doi.org/10.1172/JCl11176.

85. Li P, Schwarz EM, O'Keefe RJ, Ma L, Looney RJ, Ritchlin CT, et al. Systemic tumor necrosis factor alpha mediates an increase in peripheral CD11b high osteoclast precursors in tumor necrosis factor alpha-transgenic mice. Arthritis Rheum. 2004;50(1):265-76. https://doi.org/10.1002/art.11419.

86. Poli V, Balena R, Fattori E, Markatos A, Yamamoto M, Tanaka H, et al. Interleukin-6 deficient mice are protected from bone loss caused by estrogen depletion. EMBO J. 1994;13(5):1 189-96. https://doi.org/10.1002/j.14 60-2075.1994.tb06368.x.

87. Fujisaki K, Tanabe N, Suzuki N, Kawato T, Takeichi O, Tsuzukibashi O, et al. Receptor activator of NF-kappaB ligand induces the expression of carbonic anhydrase II, cathepsin K, and matrix metalloproteinase-9 in osteoclast precursor RAW264.7 cells. Life Sci. 2007:80(14):1311-8. https://doi.org/10.101 6/j.lfs.2006.12.037.

88. Yamamoto $Y$, Udagawa N, Matsuura S, Nakamichi Y, Horiuchi H, Hosoya A et al. Osteoblasts provide a suitable microenvironment for the action of receptor activator of nuclear factor-kappaB ligand. Endocrinology. 2006; 147(7):3366-74. https://doi.org/10.1210/en.2006-0216.

89. Guss JD, Horsfield MW, Fontenele FF, Sandoval TN, Luna M, Apoorva F, et al. Alterations to the gut microbiome impair bone strength and tissue material properties. J Bone Miner Res. 2017;32(6):1343-53. https://doi.org/10.1002/ jbmr.3114.

90. Nakamichi Y, Udagawa N, Horibe K, Mizoguchi T, Yamamoto Y, Nakamura T, et al. VDR in osteoblast-lineage cells primarily mediates vitamin $D$ treatment-induced increase in bone mass by suppressing bone resorption. $J$ Bone Miner Res. 2017;32(6):1297-308. https://doi.org/10.1002/jbmr.3096.

91. Turner AG, Hanrath MA, Morris HA, Atkins GJ, Anderson PH. The local production of $1,25(\mathrm{OH})_{2} \mathrm{D}_{3}$ promotes osteoblast and osteocyte maturation. J Steroid Biochem Mol Biol. 2014;144(Pt A):114-8.

92. van der Meijden K, Lips P, van Driel M, Heijboer AC, Schulten EA, den Heijer $M$, et al. Primary human osteoblasts in response to 25 -hydroxyvitamin $D_{3}$, 1,25-dihydroxyvitamin $D_{3}$ and 24R,25-dihydroxyvitamin $D_{3}$. PLoS One. 2014; 9(10):e110283. https://doi.org/10.1371/journal.pone.0110283.

93. Lieben $\mathrm{L}$, Carmeliet $\mathrm{G}$. The delicate balance between vitamin $\mathrm{D}$, calcium and bone homeostasis: lessons learned from intestinal- and osteocytespecific VDR null mice. J Steroid Biochem Mol Biol. 2013;136:102-6. https:// doi.org/10.1016/j.jsbmb.2012.09.019.

94. Yang D, Anderson PH, Wijenayaka AR, Barratt KR, Triliana R, Stapledon CJM, et al. Both ligand and VDR expression levels critically determine the effect of 1alpha,25-dihydroxyvitamin- $\mathrm{D}_{3}$ on osteoblast differentiation. J Steroid Biochem Mol Biol. 2018;177:83-90. https://doi. org/10.1016/j.jsbmb.2017.09.005.

\section{Ready to submit your research? Choose BMC and benefit from}

- fast, convenient online submission

- thorough peer review by experienced researchers in your field

- rapid publication on acceptance

- support for research data, including large and complex data types

- gold Open Access which fosters wider collaboration and increased citations

- maximum visibility for your research: over $100 \mathrm{M}$ website views per year

At BMC, research is always in progress.

Learn more biomedcentral.com/submissions 